\title{
Behaviour of recycled tyre polymer fibre reinforced concrete under dynamic splitting tension
}

\author{
Meng Chen ${ }^{\mathrm{a}, \mathrm{b}}$, Hui Zhong ${ }^{\mathrm{c}}$, Hao Wang ${ }^{\mathrm{b}}$, Mingzhong Zhang ${ }^{\mathrm{c}, *}$ \\ ${ }^{a}$ School of Resources and Civil Engineering, Northeastern University, Shenyang 110819, China \\ ${ }^{\mathrm{b}}$ Science and Technology Innovation Center of Smart Water and Resource Environment, \\ Northeastern University, Shenyang 110819, China \\ ${ }^{\mathrm{c}}$ Department of Civil, Environmental and Geomatic Engineering, University College London, \\ London WC1E 6BT, UK
}

\begin{abstract}
Recycled tyre polymer (RTP) fibre has recently been gaining ever-increasing attention from the scientific community as a promising substitute to synthetic fibres for cementitious composites to improve sustainability. This paper, for the first time, investigates the behaviour of RTP fibre reinforced concrete (FRC) under dynamic splitting tension, focusing on the effects of fibre content $(0.1,0.2,0.4$ and $0.8 \mathrm{vol} \%)$ and strain rate $\left(0.88-3.54 \mathrm{~s}^{-1}\right)$ and the feasibility of replacing polypropylene (PP) fibre with RTP fibre for FRC. Results indicate that the inclusion of RTP fibres is favourable in enhancing the splitting tensile properties of concrete under various strain rates $\left(10^{-1}\right.$ to $10^{1} \mathrm{~s}^{-1}$ ), where the dynamic splitting tensile strength and dissipated energy of concrete mixture containing 0.2 vol\% RTP fibre are improved by $5.5 \%-14.2 \%$ and $24.9 \%-36.7 \%$ respectively compared to the plain mixture as a result of fibre bridging effect. Fibre pull-out process considerably contributes to the enhancement of energy dissipation capacity. The splitting tensile properties of all mixtures are sensitive to strain rate, where the developed empirical equations well describing the relationship between dynamic increase factor (DIF) and strain rate provide insight into this rate sensitivity. A comparison between RTP-FRC and PP-FRC confirms that RTP fibre can be used as a sustainable and cost-effective alternative to PP fibre for cementitious materials considering engineering properties and potential economic benefit of the composites.
\end{abstract}

Keywords: Fibre reinforced concrete; Recycled fibre; Polypropylene fibre; Dynamic properties; Strain rate effect; Split Hopkinson pressure bar

\footnotetext{
* Corresponding author. E-mail address: mingzhong.zhang@ucl.ac.uk (M. Zhang)
} 


\section{Introduction}

It was reported that about 1.5 billion end-of-life tyres are produced every year [1] and this amount is expected to increase with the increasing number of vehicles. The amount may reach 5 billion by 2030 $[2,3]$, while most of the waste tyres would be landfilled, stockpiled or burned. These disposal methods may induce several environmental problems such as the production of harmful substances, air and soil pollution, and source of forming disease [2, 4]. Given that creating a sustainable development path for the present and future generations in various aspects is one of the main goals in this century $[\underline{5}, \underline{6}]$, it is essential to dispose the waste tyres in a more eco-friendly way.

Apart from the aforementioned disposal methods, another method of disposing waste tyres is to recover their constituent materials via several processing phases [7]. The recovered materials mainly include rubber, steel and polymer fibre. In recent years, an increasing number of studies have attempted to apply these recycled tyre materials in the field of civil engineering especially the mix design of concrete, in order to promote the sustainable development in the construction industry through maximising the usage of recycled materials. For instance, depending on the size of rubber, it can be used to partially replace fine or coarse aggregates in concrete, which is known as rubber concrete [2]. Compared to conventional concrete, rubber concrete generally exhibits lower unit weight, better impact behaviour and improved durability, which can be used for pavements or barriers $[\underline{2}, \underline{8}]$. Steel is a major component of the tyre (13\%-27\%) [9]. It was found that concrete reinforced with recycled tyre steel fibres is comparable with that reinforced with manufactured steel fibres under a certain fibre dosage $[\underline{10}, \underline{11]}$. Besides, recycled tyre polymer (RTP) fibre is another major recovered material from the waste tyre. It was reported that approximately 250,000 tonnes of RTP fibres are generated annually in the EU region [12]. RTP fibre is highly flammable, safely storing it is a big challenge [12]. Therefore, finding an appropriate way of disposing RTP fibres is of interest to researchers.

Recently, an increasing number of studies have investigated the engineering properties of concrete reinforced with RTP fibres. A summary of these studies is listed in Table 1. Most of the research aimed at evaluating the optimal RTP fibre content in fibre reinforced concrete (FRC) considering the effects of RTP fibre content on the physical, mechanical and durability properties of concrete. The feasibility of using RTP fibres as an alternative to manufactured PP fibres for cement-based materials is also a research focus. For instance, Huang et al. [13] studied the effect of RTP fibre content (1-7 
$\mathrm{kg} / \mathrm{m}^{3}$ ) on the mechanical behaviour of concrete after fire spalling and found that concrete incorporating RTP fibres over $2 \mathrm{~kg} / \mathrm{m}^{3}$ exhibited superior fibre spalling resistance. The experimental studies on shrinkage of RTP-FRC indicated that under a certain RTP fibre dosage, the resistances to autogenous and plastic shrinkage were enhanced $[14, \underline{15]}$. The effects of as-received (without any cleaning process before usage) and cleaned (with certain cleaning process before usage) RTP fibres on the engineering properties of normal and wet-sprayed concrete were explored by Baricevic et al. $[12, \underline{16}]$, who reported that independent of RTP fibre type, incorporating a certain dosage of RTP fibres can significantly restrain the early-age deformation and enhance the freeze-thaw resistance, while the workability and compressive strength were not considerably influenced. Onuaguluchi and Banthia [17] found that the synergistic effects in post-crack flexural behaviour were formed when RTP fibres were combined with either steel or PP fibres. However, these studies mainly focused on the static properties of RTP-FRC. During service, concrete structures are not only subjected to the static loadings but may experience several time-varying loadings with high strain rates, e.g., earthquake and impact. In some military zones, concrete structures may encounter blast or explosion forces [18]. Thus, it is vital to understand the behaviour of RTP-FRC under a wide range of strain rates corresponding to the above loading conditions. As presented in Table 1, Chen et al. [19, 20] investigated the effect of four different RTP dosages (0.1-0.8 vol\%) on the dynamic compressive properties and flexural fatigue behaviour of concrete and observed that incorporating 0.2 vol\% RTP fibre improved the compressive strength and energy absorption capacity under various strain rates by about $12.9 \%$ and $54.4 \%$, respectively. In addition, the flexural fatigue behaviour was enhanced with the addition of RTP fibres. It is worth mentioning that the tensile failure of concrete under extreme loading conditions (e.g. medium or high strain rate loadings) may be more pronounced than compressive failure due to its inherent low tensile properties implying that, understanding the tensile behaviour under different strain rates is crucial. However, to the best of authors' knowledge (see Table 1), the tensile behaviour of concrete reinforced with RTP fibres under a range of medium or high strain rates (over $10^{-1} \mathrm{~s}^{-1}$ ) has not been assessed. Therefore, it is important to provide a comprehensive understanding of the effects of RTP fibres and strain rates on the tensile behaviour of RTP-FRC for its potential engineering applications.

The main purpose of this study is to experimentally investigate the effect of RTP fibre content $(0.1,0.2,0.4$ and 0.8 vol\%) on the static and dynamic splitting tensile properties of concrete. The 
mixture containing 0.1 vol\% PP fibre was regarded as the reference for comparison to seek whether RTP-FRC presents better splitting tensile behaviour than PP-FRC considering a range of strain rates. First, a series of tests were carried out to measure the workability, static splitting tensile strength and elastic modulus of specimens with various fibre contents, based on which the effect of fibres was estimated. Then, the splitting tensile properties including stress-time curves, failure patterns and dissipated energy under various strain rates $\left(0.88-3.54 \mathrm{~s}^{-1}\right)$ were measured using a $100 \mathrm{~mm}$ diameter split Hopkinson pressure bar (SHPB) testing setup. The obtained results were compared with that of static splitting tensile test to estimate the effects of fibres and strain rates on the dynamic increase factor (DIF) of concrete. Reliable predicted equations considering the relationship between DIF and strain rate were developed. Afterwards, scanning electron microscope (SEM) was utilised to characterise the morphology of RTP fibres in concrete after the SHPB test. Lastly, a comparison between RTP-FRC and PP-FRC considering workability and static and dynamic mechanical properties was made to gain insight into the reinforcing mechanisms.

\section{Experimental program}

\subsection{Materials}

Portland cement (P.I. 42.5) with a specific gravity of 3.09 was used in this study, the chemical composition of which is given in Table 2. Natural river sand and crushed granites were used as the fine and coarse aggregates, respectively. The specific gravity of fine aggregates is 2.56 . The maximum size of coarse aggregates is $20 \mathrm{~mm}$. Polycarboxylate-based superplasticiser (SP) was added at $1.0 \%$ by the mass of cement content for all mixtures to improve the workability of specimens. RTP and PP fibres shown in Fig. 1 were adopted as reinforcing materials. It can be observed from the SEM micrographs of the fibres in Fig. 1c and d that RTP fibres are not uniform in dimension, while the shape of PP fibres is straight. It should be noted that RTP fibres were used as received in this study and thus many rubber particles are attached. To better understand the percentage of attached rubber particles of as-received RTP fibres, a simplified laboratory sieving method based on a previous study [12] was applied and a detailed testing process was reported in authors' previous research [20]. It was found that the as-received RTP fibres contain 56.8\% cleaned RTP fibres and $43.2 \%$ rubber particles by weight $[19,20]$. Table 3 illustrates the physical and mechanical properties of RTP and PP fibres, which are the same as those used in the previous studies [19, 20]. Here, the dimension of RTP fibres was characterised based on a group of samples using a microscope and a fibre diameter tester (XGD- 
1 Fibre Diameter Tester), the results of which are presented in Fig. 2. It is worth noting that 500 and 300 samples were used for the characterisation of length and diameter of RTP fibres, respectively. The coefficient of variations (COV) for the length and diameter of RTP fibres were $47.1 \%$ and $11.8 \%$, respectively. More details about the geometrical characteristics of RTP fibres can be found in authors' previous studies $[\underline{19}, \underline{20}]$. Fibre tensile tester (XQ-1A Fibre Tensile Tester) was used to measure the mechanical properties of RTP fibres shown in Table 3.

2.2 Mix proportions and sample preparation

The mix proportions presented in Table 4 were designed in accordance with the authors' previous studies $[19,20]$. The influencing parameters in this study were fibre type (PP and RTP fibres) and fibre volume fraction (0.1-0.8 vol\%). The number denoted in the symbol (e.g. '09' in PPF09 and '12' in RTPF12) stands for the fibre content in $\mathrm{kg} / \mathrm{m}^{3}$. Herein, 0.9 and $1.2 \mathrm{~kg} / \mathrm{m}^{3}$ correspond to about 0.1 vol\% for PP fibre and RTP fibre, respectively. It was reported that incorporating PP fibres with equal or less than $0.1 \mathrm{vol} \%$ into concrete can achieve the optimal mechanical properties of resultant composites with improved early-age shrinkage resistance and compressive behaviour under a range of high strain rates $[\underline{12}, \underline{19}, \underline{21}, \underline{22}]$. In addition, RTP fibres showed great potential as a substitute of PP fibres considering the performances of the resultant composites but higher dosages of RTP fibres are required $[\underline{12}, \underline{14}, \underline{19}, \underline{20}]$. To date, a comparison between RTP-FRC and PP-FRC in terms of tensile behaviour under various strain rates has not been studied. Thus, the mix proportion of PP-FRC used in this study (see Table 4) was kept consistent with previous studies [12, $\underline{19}, \underline{20}]$ that concrete reinforced with 0.1 vol\% PP fibre was prepared and compared with RTP-FRC containing various RTP fibre contents.

Regarding the mixing process, dry materials including cement and fine and coarse aggregates were first mixed for $2 \mathrm{~min}$. Then, water and SP were added to the mixture followed by the gradual addition of fibres. For the mixture containing RTP fibres, the weighted RTP fibres were mixed with part of water and SP to ensure a better fibre dispersion [17, 20]. Afterwards, the fresh mixtures were poured into different moulds. After $24 \mathrm{~h}$, all samples were demoulded and cured for $28 \mathrm{~d}$ in a standard curing room $\left(20 \pm 2{ }^{\circ} \mathrm{C}\right.$ and $\left.95 \% \mathrm{RH}\right)$.

\subsection{Testing methods}

Table 5 presents the experimental program in terms of number of specimens, achievable parameter and complied standard for each test. The details about testing methods are described below. 


\subsubsection{Slump test}

Before casting, the slump test was performed to evaluate the effect of fibre on workability of concrete according to GB/T50080-2016 [23].

\subsubsection{Static splitting tensile test}

The static splitting tensile strength was evaluated using specimens with two different sizes of 150 $\mathrm{mm} \times 150 \mathrm{~mm} \times 150 \mathrm{~mm}$ and $\varnothing 100 \mathrm{~mm} \times 50 \mathrm{~mm}$, in accordance with GB/T50081-2002 [24]. For splitting tensile tests, the results are only valid when the first crack is initiated at the centre of the specimen and then propagates along the loading direction [25, 26]. Thus, Brazilian disc sample was fabricated to mitigate the above issue. Herein, two parallel flattens with equal width were produced on the specimen with a dimension of $\emptyset 100 \mathrm{~mm} \times 50 \mathrm{~mm}$ to fit the loading platens of the testing

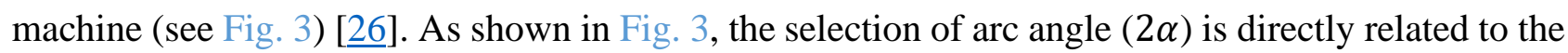
reliability of the results. As per a previous study [27], the arc angle equal or over $20^{\circ}$ can guarantee the crack would mostly occur at the centre. Therefore, in this study, an arc angle of $20^{\circ}$ was used for all the cylindrical specimens for splitting tensile tests.

For the Brazilian disc cylindrical specimen, the conventional equation of splitting tensile strength is not appropriate due to the existence of two parallel flattens [28]. Thus, the following formula was used to characterise the splitting tensile strength of Brazilian disc cylindrical specimen [27, 28]:

$$
f_{s t}=k \frac{2 F_{p}}{\pi D B}
$$

where $f_{s t}$ is the splitting tensile strength of the specimen, $F_{p}$ is the maximum load during the splitting tensile test, $D$ is the diameter of the specimen, $B$ is the depth of the specimen, and $k$ is the coefficient related to the loading angle [27], which is 0.95 for $2 \alpha=20^{\circ}$ [29].

\subsubsection{Elastic modulus test}

According to GB/T50081-2002 [24], the elastic modulus test was conducted on $150 \mathrm{~mm} \times 150 \mathrm{~mm}$ $\times 300 \mathrm{~mm}$ prismatic specimens for each mixture. The elastic modulus can be calculated as:

$$
E_{s}=\frac{\sigma_{a}-\sigma_{0}}{\varepsilon_{a}-\varepsilon_{0}}
$$

where $E_{s}$ represents the elastic modulus of the specimen, $\sigma_{a}$ is the stress corresponding to the $1 / 3$ of the ultimate stress, $\sigma_{0}$ corresponds to $0.5 \mathrm{MPa}$ during the loading, $\varepsilon_{a}$ is the longitudinal strain at $\sigma_{a}$, and $\varepsilon_{0}$ is the longitudinal strain at $\sigma_{0}$. 


\subsubsection{Split Hopkinson pressure bar test}

The splitting tensile behaviour of the specimens under various strain rates $\left(10^{-1}\right.$ to $\left.10^{1} \mathrm{~s}^{-1}\right)$ was measured using a $100 \mathrm{~mm}$ diameter SHPB testing setup, the schematic diagram of which is presented in Fig. 4. The components and the corresponding properties were the same as the SHPB setup used in a previous study [19]. The main components contain a striker bar, an incident bar, a transmitted bar and an absorbing bar, the lengths of which are 600, 5000, 3500 and $1200 \mathrm{~mm}$, respectively. These bars are made of superior alloy steel.

Before the test, the Brazilian disc specimen was sandwiched between the incident and transmission bars, as shown in Fig. 4. During the test, the incident bar was first impacted by the striker bar which produced an incident wave $\left(\varepsilon_{i}(t)\right)$. During the propagation of the incident wave, part of the incident wave was reflected as reflected wave $\left(\varepsilon_{r}(t)\right)$ when it reached the interface between bar and specimen. The remaining part was transmitted through the transmission bar as transmission wave $\left(\varepsilon_{t}(t)\right)$. A pulse shaper (see Fig. 4) was used to transform the square-shaped waveform into half-sineshaped waveform by minimising the wave dispersion $[30, \underline{31]}$. Thus, the rising time of the incident pulse can be prolonged to ensure the stress equilibrium is achieved within the specimen. The strain gauges mounted on both incident and transmission bars were used to record the details of these three waveforms [19]. The change of force with time $\left(F_{d}(t)\right)$ acting on the specimen can be calculated as follows [시, $\underline{32}]$ :

$$
F_{d}(t)=E_{0} A \varepsilon_{t}(t)
$$

where $A$ denotes the cross-sectional area of the bars, and $E_{0}$ represents the elastic modulus of the bars.

The change of stress with time $f_{d}(t)$ can be evaluated using Eq. (1) by inputting the change of force obtained from Eq. (3). The corresponding loading rate $(\dot{\sigma})$ and strain rate $(\dot{\varepsilon})$ of each tested specimen can be calculated as:

$$
\begin{aligned}
& \dot{\sigma}=\frac{f_{d s t}}{\Delta t} \\
& \dot{\varepsilon}=\frac{\dot{\sigma}}{E_{s}}
\end{aligned}
$$

where $f_{d s t}$ stands for the dynamic splitting tensile strength of the specimen (peak value), $\Delta t$ is the time for the tested specimen to reach $f_{d s t}$, and $E_{s}$ is the elastic modulus of the tested specimen.

It is worth noting that all the above equations were used based on two main assumptions that are one-dimensional wave propagation and uniformity of stress or strain [31]. The surface condition of 
RTP fibres after the SHPB test was characterised using SEM. As previously stated, the use of a pulse shaper can help achieve the stress equilibrium whilst the SHPB test. It is essential to check whether the stress equilibrium is achieved to ensure the validity of the SHPB results. Thus, an example showing how the stress equilibrium state was checked is illustrated in Fig. 5. As observed, the wave at the incident end of the tested specimen is very close to the transmitted wave, which implies that the stress equilibrium was achieved.

\section{Results and discussion}

\subsection{Static splitting tensile strength}

Fig. 6 presents the static splitting tensile strength of all mixtures. The results of the plain mixture (F0) were highlighted as purple dash lines in Fig. 6. It can be observed that, regardless of fibre type and sample size, the static splitting tensile strength of all FRC mixtures was higher than that of F0. With respect to the effect of sample size, the results obtained using cylindrical samples were found to be higher than that using cubic samples (averagely 15.2\%). This can be explained by the fact that the splitting tensile strength is dependent on the fracture area of the splitting section whilst the testing [33] meaning that, the splitting tensile strength tends to be higher when the splitting area is smaller. Regarding the effect of RTP fibre content, as seen in Fig. 6, incorporating 0.1-0.8 vol\% RTP fibre increased the static splitting tensile strength up to $7.6 \%$ as compared with F0. This could be attributed to the bridge effect of RTP fibres across the fracture zone, which restrained the crack growth and propagation [20]. As a result, the splitting tensile strength of RTP-FRC was improved. However, the improvements induced by the addition of RTP fibres were not significant, which can be attributed to the features of RTP fibres, e.g. fibre length. As seen in Table 3, the average length of RTP fibre is quite short, which may lose the efficiency of fibre bridging as the splitting cracks propagate. It is interesting to note that, similar to flexural strength [20], the further addition of RTP fibres (over 0.2 vol\%) gradually weakened the splitting tensile strength of concrete. Under the same fibre dosage $(0.1$ vol\%), the splitting tensile strength of RTP-FRC was comparable to that of PP-FRC with no more than $1.5 \%$ difference. This implies that both RTP and PP fibres were not significant in enhancing the splitting tensile strength of concrete, which can be attributed to their hydrophobic characteristics [14,

34]. Therefore, the bonding between either RTP or PP fibres and matrix tends to be poor. Although both fibres can bridge the micro cracks, they may experience slippage or pull-out as the cracks propagate, leading to a reduced load-carrying capacity of the resultant composites. 


\subsection{Elastic modulus}

Fig. 7 shows the elastic modulus of concrete with and without fibres. The result of compressive strength [19] is also illustrated for comparison as the elastic modulus of concrete is strongly related to its compressive strength $[\underline{30}, \underline{35]}$. It can be clearly found that the trend of compressive strength is consistent with that of elastic modulus that regardless of fibre type, the addition of fibres reduced the elastic modulus by $4.0 \%-15.7 \%$ as compared with F0. The results here are in good agreement with findings presented by a previous study [12] that RTP and PP fibres resulted in a decline of elastic modulus by $3.0 \%-7.0 \%$. The observed reduction in elastic modulus can be explained by the same reasons for the change in compressive strength [19, 20], which are mainly influenced by the internal structure of FRC (e.g. porosity) and stiffness of the fibre [35]. Firstly, the inclusion of fibres reduces the workability of fresh concrete. As seen in Table 4, the slump value of FRC decreased with the increase of RTP fibre content, where RTPF96 achieved the lowest slump value of $70 \mathrm{~mm}$. This can be ascribed to the increased contact network between fibre and matrix, which would restrict the movement of constituent materials [20]. The reduction in workability may increase the nonhomogeneity of FRC and thus affect its internal structure. Secondly, the porosity of FRC would be increased due to the increased air content entrapped by the rubber particles attached the RTP fibres (i.e. $0.518-4.15 \mathrm{~kg} / \mathrm{m} 3$ ). Besides, rubber particles have relatively a lower stiffness than the cement matrix [36] and thus, the cracks would be easily present along the weak interface between rubber particle and cement matrix. Moreover, the low stiffness of RTP and PP fibres partially contributes to the reduction in elastic modulus of FRC, although it was noted that the fibre stiffness does not have a significant effect on the mechanical properties of FRC prior to cracking [37].

\subsection{Dynamic splitting tensile behaviour}

\subsubsection{Dynamic splitting tensile strength and failure pattern}

Fig. 8 depicts the stress-time curves of all mixtures under various strain rates ranging from $0.88 \mathrm{~s}^{-1}$ to $3.54 \mathrm{~s}^{-1}$. In this study, the dynamic splitting tensile strength corresponds to the peak stress of the curves shown in Fig. 8, the results of which are listed in Table 6. An obvious feature can be found for all mixtures that, increasing the strain rate consistently enhanced the dynamic splitting tensile strength. For instance, for F0, the peak stress (see Fig. 8a) increased from 9.55 $\mathrm{MPa}$ to $11.73 \mathrm{MPa}$ when the strain rate rose to $1.34 \mathrm{~s}^{-1}$. Besides, for FRC, the peak stress of RTPF12 (see Fig. 8c) was improved by $19.1 \%$ when the strain rate changed from $0.94 \mathrm{~s}^{-1}$ to $1.35 \mathrm{~s}^{-1}$. This strength improvement feature 
could be influenced by several factors such as structural inertia forces and viscosity of bulk material $[\underline{38}, 39]$. In addition, the rapid development of cracks along with the appearance of multiple cracks under high strain rates is also responsible for this strength enhancement feature [38]. As shown in Fig. 8, apart from the dynamic splitting tensile strength, the increase of strain rate also resulted in a shorter time to reach the peak stress meaning that, the curves shifted towards left. When the strain rate was the lowest, the time to reach the peak stress of all mixtures was in the range between 310 and $325 \mu$ s. By contrast, the time decreased to $140-155 \mu$ s when the strain rate was the highest. This can be also observed in Table 6 that, the average stress rate of all mixtures was increased with the rising strain rate. As introduced in Section 2.3.4, the stress rate was defined as the ratio of the peak stress (see Fig. 8) to the time needed to reach it. Thus, when the time required to reach the peak stress was reduced, the corresponding stress rate increased. It is worth noting that this duration is dependent on the striker bar as well as the thickness of the pulse shaper [40].

The failure patterns of all mixtures under static and dynamic splitting tension are illustrated in Fig. 9. Given that concrete is heterogeneous in nature, the resulted strain rate for each mixture would vary even under the same impact velocity [19]. Thus, in Fig. 9, a range of strain rates are given rather than a specific strain rate. It can be clearly seen that for all mixtures, the cracks were mostly passing through the centre of the specimen surface, which confirms the validity of the results. As seen in Fig. 9, under static loading, all mixtures showed similar failure patterns that the tested samples were broken into two halves. Besides, for RTPF48 and RTPF96, some additional cracks can be observed near the loading positions, which can be ascribed to the increased stress concentration between specimen and loading ends. Under dynamic loading, unlike the failure patterns of specimens subjected to the static loading, the main crack formed along the surface of the specimen was not straight. With the increase of strain rate $\left(2.12-3.54 \mathrm{~s}^{-1}\right)$, this feature became more pronounced and the cracks from the centre was shearing towards the loading ends, forming triangular crushed sections near the two flat ends. The possible reason for this failure feature is that the cracks appear before the stress reaches the equilibrium state [25]. Additionally, the use of two flattens to fit the loading points (see Fig. 3) could relieve the stress concentration near the loading ends [25, 29], but the increased friction at the interface between specimen and loading points under high strain rates could still result in unstable stress distribution. 
Fig. 10 illustrates an example showing the effect of RTP fibres on the stress-time curves of concrete under a range of strain rates. In general, the presence of RTP fibres increased the dynamic splitting tensile strength in comparison with F0. The effect of RTP fibre content on the dynamic splitting tensile strength is shown in Fig. 11. Under various ranges of strain rate, all RTP-FRC mixtures exhibited a similar trend that the dynamic splitting tensile strength was increased initially up to a fibre dosage of $0.2 \mathrm{vol} \%$, followed by a descending trend with the further addition of RTP fibres. This trend is consistent with that of dynamic compressive strength [19]. Under an appropriate fibre content, the incorporation of RTP fibres can bridge the existing cracks and appearing cracks due to external loading, which restrains the growth of cracks. Unlike dynamic compressive failure [19], for all RTP-FRC mixtures, only one clear macro crack can be observed for dynamic splitting tensile failure (see Fig. 9). This suggests that the appearance of existing cracks inside the concrete either due to intrinsic flaws or shrinkage mechanism can largely affect its behaviour under high velocity impact as the cracks caused by the external forces are more likely present at the weak zone or near the intrinsic flaws [35]. As reported by previous studies $[\underline{12}, \underline{16}]$, under a certain fibre dosage, the inclusion of RTP fibres can effectively limit the crack growth induced by shrinkage, which indicates that the number of internal cracks would be lower when RTP fibres are present inside the concrete matrix. Besides, the improved dynamic splitting tensile strength observed in RTP-FRC is highly associated with the energy dissipation capacity. More energy is required to fracture the fibre reinforced composite because of the stress transfer at the fibre-matrix interface. In summary, the dynamic splitting tensile strength is significantly affected by the fibre bridging efficiency and internal structure of the composite. As mentioned previously, the internal structure of the composite is influenced by its internal fibre orientation. It is interesting to note that the mixture containing 0.2 vol\% RTP fibre had the highest dynamic splitting tensile strength under different ranges of strain rate, which was approximately $5.5 \%-14.2 \%$ higher than that of F0. This is consistent with the previous discussion that adding 0.2 vol\% RTP fibre can achieve the optimal fibre distribution in concrete, which enhances the mechanical properties of concrete. Regarding the post-failure pattern of all mixtures (see Fig. 9), no pronounced difference can be found as the RTP fibre content changed. Nevertheless, within the strain rate range of 1.73-2.05 s ${ }^{-1}$, several fragments can be observed for F0, which can be attributed to the stress localisation near the loading points [25]. By contrast, a secondary 
vertical crack can be noticed for RTPF24, which suggests that the presence of RTP fibres dispersed the acting stress to wider areas.

\subsubsection{Dynamic increase factor}

The strength-enhancing feature discussed in the last section is usually quantified in terms of DIF, which is defined as the ratio of dynamic splitting tensile strength to static splitting tensile strength. In this study, the static splitting tensile strength measured using cylindrical specimens was used for calculating the DIF, the results of which are listed in Table 6. It can be found that under various strain rates, all mixtures had a DIF over 1 and it consistently increased with the increasing strain rate. This is well correlated with dynamic splitting tensile strength discussed in Section 3.3.1. It is worth mentioning that acquiring an equation between DIF and strain rate is essential for better characterisation of material behaviour under high strain rate tension [30]. Besides, a reliable equation can provide more insights for future structural design and numerical analysis. Thus, the fitted linear curves of DIF against strain rate for plain concrete, PP-FRC and RTP-FRC are obtained and shown in Fig. 12. The developed DIF equations are compared with those proposed by other studies [41, $\underline{42]}$ for predicting the tensile properties of steel-FRC within a certain range of strain rates, which are listed together in Table 7. Regarding the gradients of the developed equations, RTP-FRC presented the highest sensitivity to strain rate in comparison with plain concrete and PP-FRC. The $R^{2}$ shown in Table 7 can be used to judge the reliability of the developed equations, where the equations developed in this study were found to be reliable and accurate as the values of $R^{2}$ were close to $1(0.950-0.979)$. The predicted equation developed by Zhao et al. [41] showed that hybrid FRC containing steel and polyvinyl alcohol fibres was less sensitive to strain rate than the studied mixtures here (with a gradient of only 0.543$)$. Wu et al. [42] reported that the ultra-high performance concrete containing various contents of micro steel fibres presented considerably large sensitivity that the tensile strength was significantly enhanced with the rising strain rate (with a gradient of 9.635). However, the results have large deviations with $R^{2}=0.795$. The fitted equation derived by a previous study [19] for the prediction of dynamic compressive strength of RTP-FRC was also used for comparison. As seen in Fig. 12 and Table 7, the dynamic compressive strength of RTP-FRC was more sensitive to strain rate in comparison with the dynamic splitting tensile strength (with a gradient of 2.422), which is inconsistent with the finding of [41]. The possible reason could be that the static compressive strength of RTP-FRC was generally lower than that of plain concrete, i.e. up to $17.7 \%$ lower at $28 \mathrm{~d}$. According 
to the definition of DIF, the lower the static mechanical strength (i.e. smaller denominator), the higher the DIF can be achieved [19]. Moreover, utilising compressive loading condition in SHPB setup can exhibit a very high range of strain rates $\left(10^{1}\right.$ to $\left.10^{4} \mathrm{~s}^{-1}\right)[\underline{18}, \underline{22}]$, which may in turn increase the strain rate sensitivity. In contrast, the static splitting tensile strength of RTP-FRC found in this study was higher than that of F0 and the resulted strain rates were in the range between $10^{-1}$ and $10^{1} \mathrm{~s}^{-1}$. As a result, the strain rate sensitivity may be slightly affected. Nevertheless, both equations were found to be reliable for predicting the compressive and tensile behaviour of RTP-FRC within a certain range of strain rates as the $R^{2}$ values were both higher than 0.9 .

Fig. 13 presents the effect of RTP fibre content on the DIF under different ranges of strain rate, which shows a similar trend with that displayed in Fig. 11. Concrete mixture reinforced with 0.2 vol\% RTP fibre had the highest sensitivity to strain rate as the DIF of RTPF24 was the highest under various strain rates, ranging from 1.82-2.76. When the incorporated RTP fibre content was 0.8 vol\%, RTPFRC was found to be less strain rate sensitive than F0. For instance, when the strain rate range was 1.34-1.48 s $\mathrm{s}^{-1}$, the DIF of RTPF96 was 1.94 which was 0.1 lower than that of F0. This can be mainly attributed to the reduced dynamic splitting tensile strength of RTPF96 as compared with F0 (6.6\% lower). While the static splitting tensile strength of RTPF96 was comparable with that of F0, with a difference of only $1.9 \%$. Thus, considering the definition of DIF, the lower the numerator (i.e. dynamic splitting tensile strength), the smaller the DIF. Additionally, fibre failure pattern may partially contribute to the reduced DIF when the critical fibre dosage is exceeded [43].

\subsubsection{Energy dissipation capacity}

The dissipated energy of all mixtures during the SHPB test $\left(W_{d}(t)\right)$ can be calculated based on the energy balance between the energy of the incident $\left(W_{i}(t)\right)$, reflected $\left(W_{r}(t)\right)$ and transmitted waves $\left(W_{t}(t)\right)$ using the following equations [29, 31]:

$$
\begin{aligned}
& W_{d}(t)=W_{i}(t)-W_{r}(t)-W_{t}(t) \\
& W_{i}(t)=E_{0} C_{0} A \int_{0}^{t} \varepsilon_{i}^{2}(t) d t \\
& W_{r}(t)=E_{0} C_{0} A \int_{0}^{t} \varepsilon_{r}^{2}(t) d t \\
& W_{t}(t)=E_{0} C_{0} A \int_{0}^{t} \varepsilon_{t}^{2}(t) d t
\end{aligned}
$$

where $C_{0}$ denotes the longitudinal wave velocity of the bars. 
The dissipated energy of all mixtures is given in Table 6. For all mixtures, the trends of dissipated energy are consistent with those of dynamic splitting tensile strength and DIF. Increasing the strain rate consistently enhanced the dissipated energy in different extents. For instance, under the strain rate range of 2.62-3.02 $\mathrm{s}^{-1}$, the dissipated energy of F0, RTPF12, RTPF24, RTPF48, RTPF96 and PPF09 was $15.4 \%, 20.8 \%, 22.2 \%, 25.0 \%, 25.6 \%$ and $19.8 \%$ higher than that under the strain rate range of 2.12-2.52 $\mathrm{s}^{-1}$. Under high strain rate loading, the increased energy dissipation capacity for concrete can be mainly ascribed to the increasing appearance of cracks [41]. Since the loading duration is extremely short under high velocity impact, there is no enough time for the cracks to propagate. The formation of cracks dissipates more energy than the propagation, and thus the energy dissipation capacity is considerably enhanced. In this study, the failure specimen is normally fractured into parts (see Fig. 9), while Zhao et al. [41] found that the tested specimens showed fragmental failure when the strain rate was higher than $10.1 \mathrm{~s}^{-1}$. Nevertheless, in this study, the highest strain rate was around $3.54 \mathrm{~s}^{-1}$ and no obvious fragmental failure pattern was observed for the specimens shown in Fig. 9. The highest energy improvement due to the rising strain rate obtained in this study $(61.0 \%)$ was much lower than that for the energy dissipation of RTP-FRC under dynamic compression reported in [19] that was $339.3 \%$. It can be suggested that the improved dissipated energy with the increase of strain rate can be attributed to the formation of internal micro cracks and propagation of primary splitting crack (see Fig. 15).

As mentioned in Section 3.3.1, fibre bridging behaviour plays an important role in improving the tensile behaviour of FRC under different strain rates. For FRC, the energy dissipated by the pull-out process of fibres accounts for a large proportion of total energy dissipation capacity under dynamic loading $[\underline{19}, \underline{44}$. It is worth pointing out that various fibre characteristics including chemical bond, frictional bond and anchorage can influence the fibre pull-out process [44, 45]. Fig. 14 illustrates the effect of RTP fibre content on the dissipated energy of concrete under various strain rates. The trend is well correlated with the trends found in Figs. 11 and 13. Similarly, RTPF24 had the highest energy dissipation of 46.6-166.1 J under different strain rates. Compared to F0, the dissipated energy of RTPF24 was improved by $24.9 \%-36.7 \%$, which further proves that 0.2 vol\% can be regarded as the optimal fibre dosage for RTPF. The improved energy dissipation capacity of RTP-FRC is highly associated with fibre pull-out behaviour. Fig. 15 shows the SEM micrographs of RTP fibres after the SHPB test. As seen in Fig. 15a, the splitting tensile failure can be ascribed to the combined formation 
of micro and macro cracks. Besides, ruptured RTP fibre can be found near the macro crack. Fig. 15b provides more information regarding the ruptured type of RTP fibres. Unlike polyvinyl alcohol fibres, RTP and PP fibres are similar, and both have a very low chemical bond. Thus, the frictional bond is the main factor influencing the pull-out process of RTP fibres. As seen in Fig. 15b, two types of ruptured end can be observed for RTP fibres, i.e. ruptured necking end and smooth end. The fibre with a ruptured necking end implies that more energy may be required to overcome the frictional bond during pull-out to cause this type of fibre failure [41]. A higher load is required to cause the fibre pull-out under dynamic loading than under static loading because of the strain rate sensitivity [46]. In contrast, less energy may be consumed to cause a fibre failure with a smooth end due to its smoother pull-out process. However, both mechanisms greatly contribute to the improvement of dissipated energy of RTP-FRC under high strain rate loading.

\subsection{Comparison between RTP and PP fibres}

One of the objectives of this study is to explore whether PP fibres can be fully replaced with RTP fibres for concrete in terms of splitting tensile properties under various strain rates. If RTP-FRC can present comparable or even better performance than PP-FRC under a certain fibre dosage, it means RTP fibres have a large potential to substitute PP fibres. As discussed above, concrete mixture with 0.2 vol\% RTP fibre has the highest dynamic splitting tensile strength, DIF and energy dissipation capacity among all mixtures. Thus, in this section, only the results of PPF09, RTPF12 and RTPF24 were used for comparison and analysis. Fig. 16 depicts the effects of PP and RTP fibres on dynamic splitting tensile strength of concrete under different strain rates. It can be observed that when the fibre dosage was $0.1 \mathrm{vol} \%$, PP-FRC slightly outperformed RTP-FRC. However, the difference was not significant (less than 5.7\%). FRC containing 0.2 vol\% RTP fibre consistently outperformed PPF09 under different ranges of strain rate, where the difference ranged from $2.7 \%-5.2 \%$. Similar results were found in the aspect of DIF shown in Fig. 17. As discussed in Section 3.3.2, RTP-FRC is more strain rate sensitive than PP-FRC, which means in overall, the increase in splitting tensile strength was higher within a certain range of strain rates. The effects of PP and RTP fibres on the dissipated energy are shown in Fig. 18. The dissipated energy of RTPF12 was considerably lower than that of PPF09, especially within the strain rate of 1.73-1.96 $\mathrm{s}^{-1}(17.6 \%)$. However, increasing RTP fibre content can slightly mitigate this negative influence. RTPF24 had at most $8.9 \%$ higher dissipated energy than PPF09. It is worth noting that the above increase or decrease percentages were estimated 
based on the average value of each parameter. Overall, the behaviour of RTPF24 and PPF09 seems to be similar.

Manufactured PP fibre can offer many benefits to cementitious materials, especially plastic shrinkage resistance [34] and it is considered as the secondary reinforcement in conventional concrete [22]. However, the production of synthetic PP fibres consumes many non-renewable and expensive natural resources, and its non-biodegradable disposal may increase the waste generation [6]. This implies that increasing the usage of PP fibres in concrete would accordingly reduce the sustainability of construction materials. Thus, it is vital to explore the feasibility of using RTP fibres as a promising substitute to manufactured PP fibres considering the engineering properties of concrete. If this hypothesis can be proved, a win-win outcome can be obtained that the manufacture of PP fibres can be reduced, and the accumulated waste tyres can be effectively disposed. As a result, the environmental impact of FRC can be considerably reduced.

Fig. 19 shows a comprehensive comparison between PPF09 and RTPF12/RTPF24 in the aspects of workability and static and dynamic mechanical properties. The results obtained from the previous studies $[19,20]$ were used and presented in Fig. 19. It should be mentioned that the percentages shown in Fig. 19 were calculated based on the average result of each parameter. Regarding the fresh properties, RTPF12 presented slightly better workability than PPF09, while the workability of RTPF24 was approximately 5.1\% lower than that of PPF09. Herein, it can be suggested that PP fibres had a more negative influence on workability than RTP fibres. The workability of FRC can be considerably affected by the critical fibre dosage while this value reduces with the increasing fibre aspect ratio [35]. According to the fibre properties shown in Table 3, PP fibre has a larger aspect ratio (731) than RTP fibre (412) implying that the critical fibre dosage of PP fibre is lower. It is worth noting that the possibility of fibre clumping may increase when the critical fibre dosage is exceeded, which may in turn reduce the workability of concrete $[\underline{35}, \underline{47}]$. The air content of RTPF12 and RTPF24 was lower than that of PPF09 due to larger surface area of PP fibres [20]. As shown in Fig. 19, all mixtures exhibited comparable static mechanical properties (compressive, flexural and splitting tensile strengths) with the largest difference of $4.8 \%$. Regarding the dynamic mechanical properties shown in Fig. 19, a range of percentages was given as various strain rates were adopted whilst the SHPB test. RTPF24 consistently had slight better static mechanical properties than PPF09, while the differences were not significant ranging from $0.8 \%-2.4 \%$. In terms of dynamic compressive 
properties, under the same fibre dosage, RTP-FRC showed less fracture energy than PP-FRC, where the largest difference was about 31.9\%. This was explained in [19] that PP fibres with a longer length can arrest the crack with a bigger size. However, increasing the RTP fibre dosage can compensate the loss in fracture energy under different strain rates, where the largest improvement over PPF-FRC was $31.4 \%$.

The estimated cost of each mixture (unit: $\mathrm{USD} / \mathrm{m}^{3}$ ) is presented in Fig. 20. The unit costs of constituent materials except RTP fibres are based on the commercial market prices [37, $\underline{48]}$. The unit cost of RTP fibres was provided by the supplier, which is around $0.5 \mathrm{USD} / \mathrm{kg}$. Since RTP fibres were used as received in this study, the potential costs of cleaning the RTP fibres before the usage was not considered. It can be found that replacing PP fibres with RTP fibres significantly reduced the overall production cost, where the cost was 5.9\%-11.8\% lower. The main difference was due to the difference in fibre costs. As a result, replacing PP fibres with RTP fibres in FRC can not only mitigate the environmental problems induced by manufactured PP fibres and accumulated waste tyres but reduce the cost of the composite. It is worth pointing out that Fig. 20 is only used to briefly indicate the potential economic benefit of using RTP fibres in concrete to replace manufactured PP fibres. For practical applications, the additional costs related to RTP fibres such as cleaning and packing costs should be considered [ $[7, \underline{12}]$. In summary, it can suggest that PP fibres should be replaced by a two times higher quantity of RTP fibres, considering the fresh and mechanical properties of FRC.

\section{Conclusions}

This study presents an experimental study on the static and dynamic splitting tensile properties of concrete with various content of recycled tyre polymer (RTP) fibre $(0.1,0.2,0.4$ and 0.8 vol\%). Splitting tensile properties of concrete with and without fibres under various strain rates $\left(0.88-3.54 \mathrm{~s}^{-}\right.$

${ }^{1}$ ) were investigated using a $100 \mathrm{~mm}$ diameter split Hopkinson pressure bar (SHPB). Based on the experimental results, the main conclusions can be drawn as follows:

- The static splitting tensile strength is influenced by the size of the tested specimen, where the tested specimen with a smaller splitting area exhibits a larger strength (averagely $15.2 \%$ higher). The addition of RTP fibres did not significantly improve the static splitting tensile strength of concrete, where adding 0.2 vol\% RTP fibres leads to the highest improvement of approximately $7.6 \%$. 
- Incorporating either RTP or PP fibres decreases the elastic modulus of concrete by $4.0 \%-15.7 \%$, which can be attributed to the increased porosity of composites, low stiffness of fibres, and low stiffness of rubber particles attached the RTP fibres.

- The dynamic splitting tensile properties including dynamic splitting tensile strength, dynamic increase factor (DIF) and energy dissipation of all mixtures investigated are sensitive to strain rate. To better understand this rate sensitivity, empirical equations with $R^{2}$ of over 0.9 were developed to describe the relationship between DIF and strain rate for all mixtures within a range of $10^{-1}$ to $10^{1} \mathrm{~s}^{-1}$.

- The incorporation of RTP fibres up to 0.2 vol\% considerably enhances the splitting tensile properties of concrete under various strain rates. For instance, the dynamic splitting tensile strength and dissipated energy are improved by 5.5\%-14.2\% and 24.9\%-36.7\%, respectively in comparison with the plain mixture without fibre.

- SEM images indicate that the dynamic splitting tensile failure is a result of the formation of internal micro cracks and macro splitting crack. In addition, RTP fibres with two different types of ruptured end can be observed after dynamic splitting tensile failure. Fibres with ruptured necking ends are mainly responsible for the enhancement of energy dissipation capacity of concrete.

- An in-depth comparison between RTP and PP fibres in terms of engineering properties and economic viability of the resultant composites indicates that PP fibres should be replaced with a two times higher content of RTP fibres in fibre reinforced concrete.

It should be mentioned that the use of as-received RTP fibres at a low fibre dosage showed improvements in static and dynamic mechanical properties, and potential environmental and economic benefits. However, stable and acceptable performance of concrete containing RTP fibres is required for engineering applications. It is essential to develop a reliable and effective cleaning approach for processing the as-received RTP fibres, as the attached rubber particles may affect the constancy of behaviour of fibre reinforced concrete $[\underline{12}, \underline{19}, \underline{20]}$. Afterwards, the addition of higher fibre dosages (e.g. 0.5-1.0 vol\%) of cleaned RTP fibres can be considered and their effects on the overall performance of concrete can then be investigated. This is a subject of ongoing work and will be presented in a future publication. 


\section{Acknowledgement}

M. Chen gratefully acknowledges the financial support of the Fundamental Research Funds for the Central Universities (No. N2001005), National Natural Science Foundation of China (No. U1602232 and No. 51774066) and Key Research and Development Program of Liaoning Province (No. 2019JH2/10300051 and No. 2019JH2/10100035). M. Zhang would like to thank the Engineering and Physical Sciences Research Council (EPSRC), UK for financial support via grant EP/R041504/1.

\section{References}

[1] G. Malarvizhi, N. Senthul, C. Kamaraj, A study on Recycling of crumb rubber and low density polyethylene blend on stone matrix asphalt, International Journal of Science and Research 2(10) (2012).

[2] B.S. Thomas, R.C. Gupta, A comprehensive review on the applications of waste tire rubber in cement concrete, Renewable and Sustainable Energy Reviews 54 (2016) 1323-1333.

[3] F. Azevedo, F. Pacheco-Torgal, C. Jesus, J.L. Barroso de Aguiar, A.F. Camões, Properties and durability of HPC with tyre rubber wastes, Construction and Building Materials 34 (2012) 186-191. [4] A. Mohajerani, L. Burnett, J.V. Smith, S. Markovski, G. Rodwell, M.T. Rahman, H. Kurmus, M. Mirzababaei, A. Arulrajah, S. Horpibulsuk, F. Maghool, Recycling waste rubber tyres in construction materials and associated environmental considerations: A review, Resources, Conservation and Recycling 155 (2020) 104679.

[5] J. Elkington, Partnerships from cannibals with forks: The triple bottom line of 21st - century business, Environ. Qual. Manage. 8(1) (1998) 37-51.

[6] R. Merli, M. Preziosi, A. Acampora, M.C. Lucchetti, E. Petrucci, Recycled fibers in reinforced concrete: A systematic literature review, Journal of Cleaner Production 248 (2019) 119207.

[7] S. Gigli, D. Landi, M. Germani, Cost-benefit analysis of a circular economy project: a study on a recycling system for end-of-life tyres, Journal of Cleaner Production 229 (2019) 680-694.

[8] H. Zhong, E.W. Poon, K. Chen, M. Zhang, Engineering properties of crumb rubber alkaliactivated mortar reinforced with recycled steel fibres, Journal of Cleaner Production 238 (2019) 117950.

[9] S. Ramarad, M. Khalid, C.T. Ratnam, A.L. Chuah, W. Rashmi, Waste tire rubber in polymer blends: A review on the evolution, properties and future, Progress in Materials Science 72 (2015) 100-140. 
[10] A. Caggiano, P. Folino, C. Lima, E. Martinelli, M. Pepe, On the mechanical response of Hybrid Fiber Reinforced Concrete with Recycled and Industrial Steel Fibers, Construction and Building Materials 147 (2017) 286-295.

[11] G. Centonze, M. Leone, M.A. Aiello, Steel fibers from waste tires as reinforcement in concrete: A mechanical characterization, Construction and Building Materials 36 (2012) 46-57.

[12] A. Baričević, M. Jelčić Rukavina, M. Pezer, N. Štirmer, Influence of recycled tire polymer fibers on concrete properties, Cement and Concrete Composites 91 (2018) 29-41.

[13] S.-S. Huang, H. Angelakopoulos, K. Pilakoutas, I. Burgess, Reused tyre polymer fibre for firespalling mitigation, Applications of Structural Fire Engineering, 2015.

[14] M. Serdar, A. Baričević, M. Jelčić Rukavina, M. Pezer, D. Bjegović, N. Štirmer, Shrinkage Behaviour of Fibre Reinforced Concrete with Recycled Tyre Polymer Fibres, International Journal of Polymer Science 2015 (2015) 1-9.

[15] O. Onuaguluchi, N. Banthia, Durability performance of polymeric scrap tire fibers and its reinforced cement mortar, Materials and Structures 50(2) (2017).

[16] A. Baricevic, M. Pezer, M. Jelcic Rukavina, M. Serdar, N. Stirmer, Effect of polymer fibers recycled from waste tires on properties of wet-sprayed concrete, Construction and Building Materials 176 (2018) 135-144.

[17] O. Onuaguluchi, N. Banthia, Value-added reuse of scrap tire polymeric fibers in cement-based structural applications, Journal of Cleaner Production 231 (2019) 543-555.

[18] D.-Y. Yoo, N. Banthia, Impact resistance of fiber-reinforced concrete - A review, Cement and Concrete Composites 104 (2019) 103389.

[19] M. Chen, W. Chen, H. Zhong, D. Chi, Y. Wang, M. Zhang, Experimental study on dynamic compressive behaviour of recycled tyre polymer fibre reinforced concrete, Cement and Concrete Composites 98 (2019) 95-112.

[20] M. Chen, H. Zhong, M. Zhang, Flexural fatigue behaviour of recycled tyre polymer fibre reinforced concrete, Cement and Concrete Composites 105 (2020) 103441.

[21] Z. Sun, Q. Xu, Microscopic, physical and mechanical analysis of polypropylene fiber reinforced concrete, Materials Science and Engineering: A 527(1) (2009) 198-204. 
[22] H. Zhang, L. Wang, K. Zheng, T.J. Bakura, P.G. Totakhil, Research on compressive impact dynamic behavior and constitutive model of polypropylene fiber reinforced concrete, Construction and Building Materials 187 (2018) 584-595.

[23] GB/T50080-2016, Testing Methods of Workability of Normal Concrete, China Building Materials Academy, China, 2016.

[24] GB/T50081-2002, Testing Methods of Mechanical Properties of Normal Concrete, China Building Materials Academy, China, 2002.

[25] X. Chen, L. Ge, J. Zhou, S. Wu, Dynamic Brazilian test of concrete using split Hopkinson pressure bar, Materials and Structures 50(1) (2016).

[26] Y. Liu, F. Dai, N. Xu, T. Zhao, P. Feng, Experimental and numerical investigation on the tensile fatigue properties of rocks using the cyclic flattened Brazilian disc method, Soil Dyn. Earthquake Eng. 105 (2018) 68-82.

[27] Q.Z. Wang, X.M. Jia, S.Q. Kou, Z.X. Zhang, P.A. Lindqvist, The flattened Brazilian disc specimen used for testing elastic modulus, tensile strength and fracture toughness of brittle rocks: analytical and numerical results, Int. J. Rock Mech. Min. Sci. 41(2) (2004) 245-253.

[28] P. Pei, F. Dai, Y. Liu, M. Wei, Dynamic tensile behavior of rocks under static pre-tension using the flattened Brazilian disc method, Int. J. Rock Mech. Min. Sci. 126 (2020) 104208.

[29] W. Feng, F. Liu, F. Yang, L. Li, L. Jing, Experimental study on dynamic split tensile properties of rubber concrete, Construction and Building Materials 165 (2018) 675-687.

[30] M.Z.N. Khan, Y. Hao, H. Hao, F.u.A. Shaikh, Mechanical properties and behaviour of highstrength plain and hybrid-fiber reinforced geopolymer composites under dynamic splitting tension, Cement and Concrete Composites 104 (2019) 103343.

[31] W. W. Chen, B. Song, Split Hopkinson (Kolsky) Bar: Design, Testing and Applications, 2011. [32] D. Chen, F. Liu, F. Yang, L. Jing, W. Feng, J. Lv, Q. Luo, Dynamic compressive and splitting tensile response of unsaturated polyester polymer concrete material at different curing ages, Construction and Building Materials 177 (2018) 477-498.

[33] V. Kadleček, S. Modrý, V. Kadleček, Size effect of test specimens on tensile splitting strength of concrete: general relation, Materials and Structures 35(1) (2002) 28.

[34] H.R. Pakravan, T. Ozbakkaloglu, Synthetic fibers for cementitious composites: A critical and in-depth review of recent advances, Construction and Building Materials 207 (2019) 491-518. 
[35] N. Ranjbar, M. Zhang, Fiber-reinforced geopolymer composites: A review, Cement and Concrete Composites 107 (2020) 103498.

[36] A. Benazzouk, O. Douzane, K. Mezreb, M. Quéneudec, Physico-mechanical properties of aerated cement composites containing shredded rubber waste, Cement and Concrete Composites 28(7) (2006) 650-657.

[37] D. Zhang, J. Yu, H. Wu, B. Jaworska, B.R. Ellis, V.C. Li, Discontinuous micro-fibers as intrinsic reinforcement for ductile Engineered Cementitious Composites (ECC), Composites Part B: Engineering 184 (2020) 107741.

[38] L. Tang, W. Zhou, X. Liu, G. Ma, M. Chen, Three-dimensional mesoscopic simulation of the dynamic tensile fracture of concrete, Eng. Fract. Mech. 211 (2019) 269-281.

[39] Y. Hao, H. Hao, G.P. Jiang, Y. Zhou, Experimental confirmation of some factors influencing dynamic concrete compressive strengths in high-speed impact tests, Cement and Concrete Research 52 (2013) 63-70.

[40] A. Bagher Shemirani, R. Naghdabadi, M.J. Ashrafi, Experimental and numerical study on choosing proper pulse shapers for testing concrete specimens by split Hopkinson pressure bar apparatus, Construction and Building Materials 125 (2016) 326-336.

[41] X. Zhao, Q. Li, S. Xu, Contribution of steel fiber on the dynamic tensile properties of hybrid fiber ultra high toughness cementitious composites using Brazilian test, Construction and Building Materials 246 (2020) 118416.

[42] H. Wu, G.M. Ren, Q. Fang, J.Z. Liu, Effects of steel fiber content and type on dynamic tensile mechanical properties of UHPCC, Construction and Building Materials 173 (2018) 251-261.

[43] L. Yang, X. Lin, R.J. Gravina, Evaluation of dynamic increase factor models for steel fibre reinforced concrete, Construction and Building Materials 190 (2018) 632-644.

[44] Z. Xu, H. Hao, H.N. Li, Dynamic tensile behaviour of fibre reinforced concrete with spiral fibres, Materials \& Design 42 (2012) 72-88.

[45] M. Mastali, A. Dalvand, A.R. Sattarifard, Z. Abdollahnejad, M. Illikainen, Characterization and optimization of hardened properties of self-consolidating concrete incorporating recycled steel, industrial steel, polypropylene and hybrid fibers, Composites Part B: Engineering 151 (2018) 186200. 
[46] N. Wang, S. Mindess, K. Ko, Fibre reinforced concrete beams under impact loading, Cement and Concrete Research 26(3) (1996) 363-376.

[47] H. Zhong, M. Zhang, Experimental study on engineering properties of concrete reinforced with hybrid recycled tyre steel and polypropylene fibres, Journal of Cleaner Production 259 (2020) 120914. [48] L. Li, W. Liu, Q. You, M. Chen, Q. Zeng, C. Zhou, M. Zhang, Relationships between microstructure and transport properties in mortar containing recycled ceramic powder, Journal of Cleaner Production 263 (2020) 121384. 

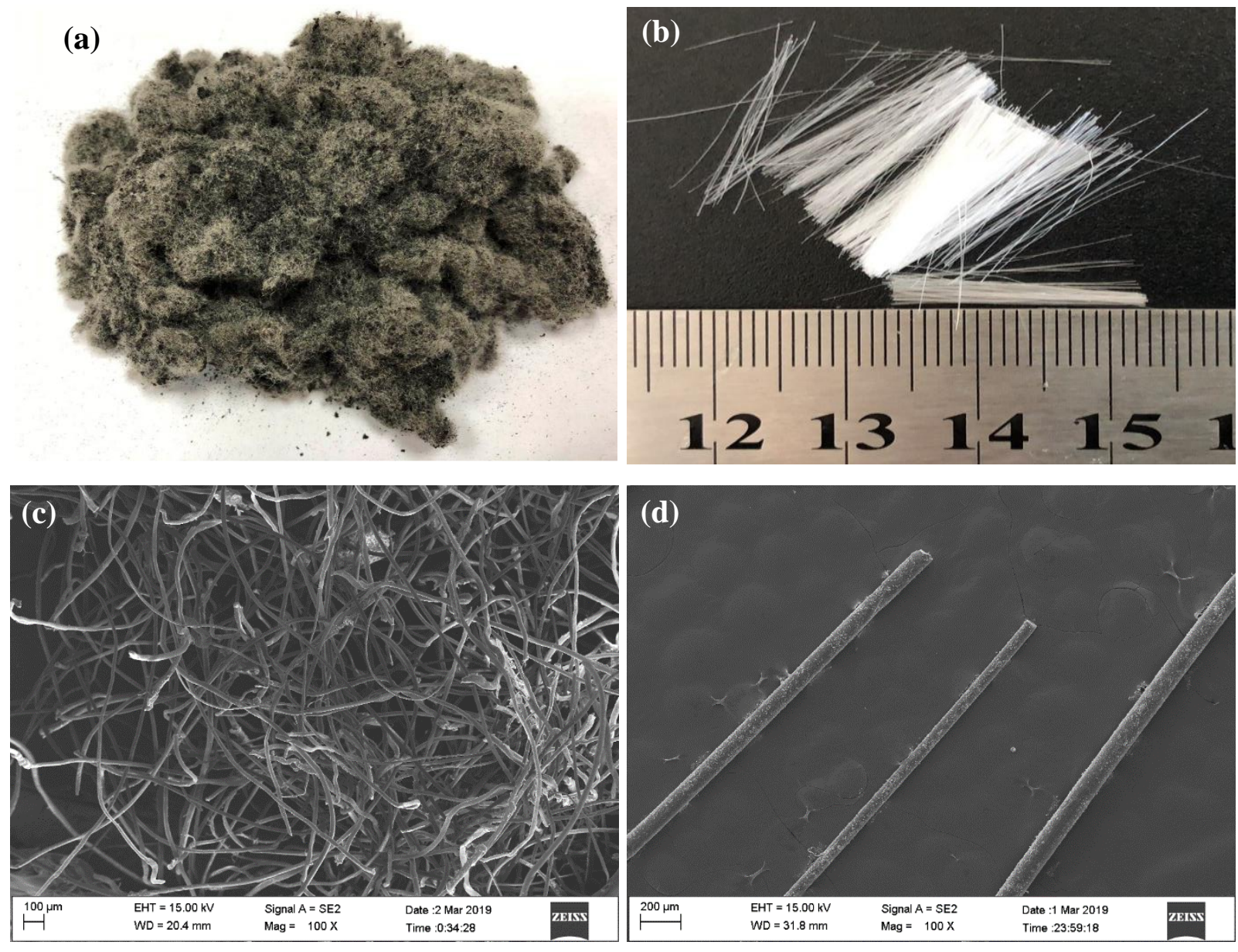

Fig. 1. Pictures and SEM micrographs of (a) as-received recycled tyre polymer (RTP) fibres (with rubber granules attached); (b) Polypropylene (PP) fibres; (c) SEM micrograph of RTP fibres (magnification: 100×); (d) SEM micrograph of PP fibres (magnification: 100×). 

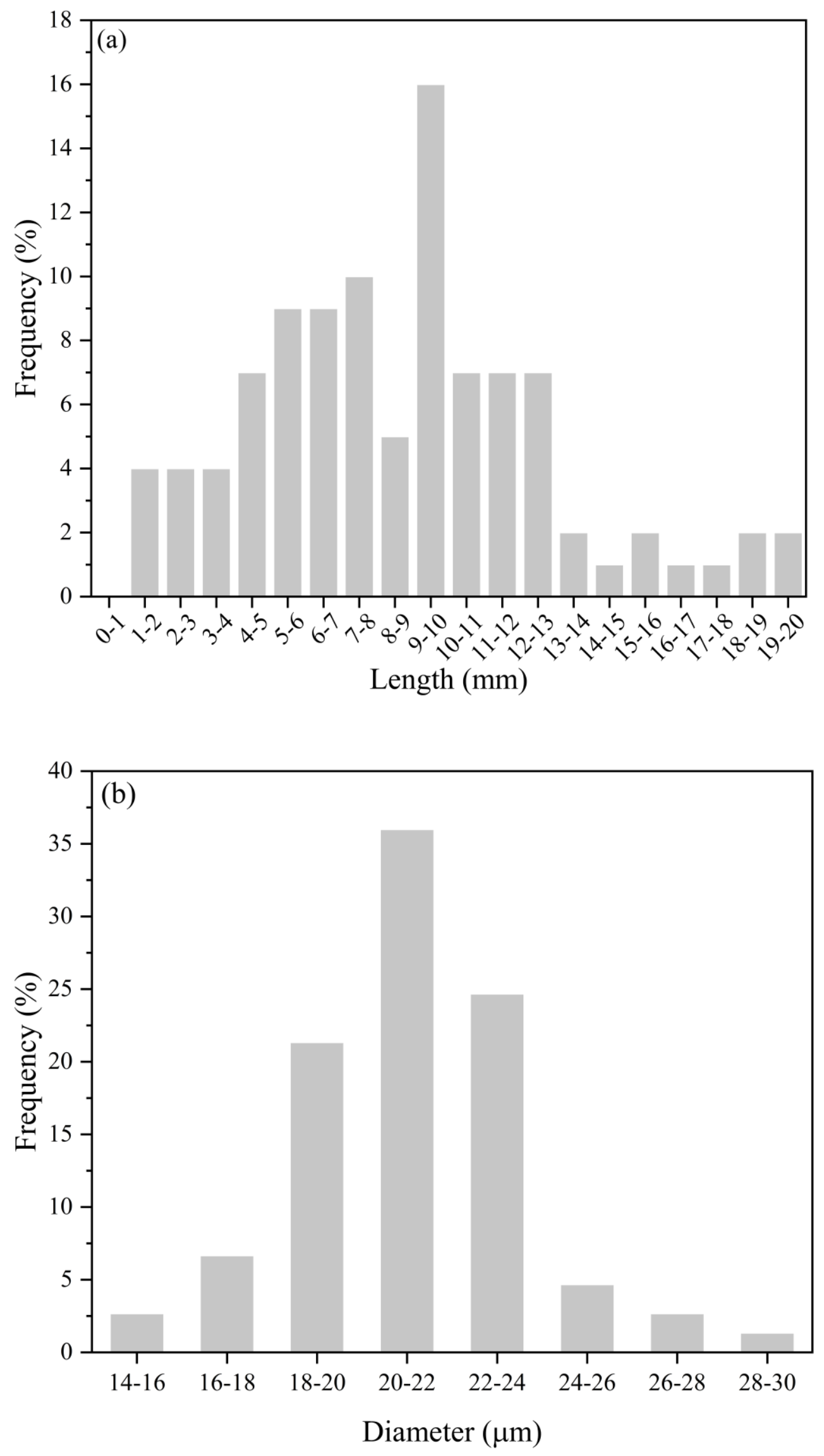

Fig. 2. Distribution of (a) length and (b) diameter of RTP fibre. 


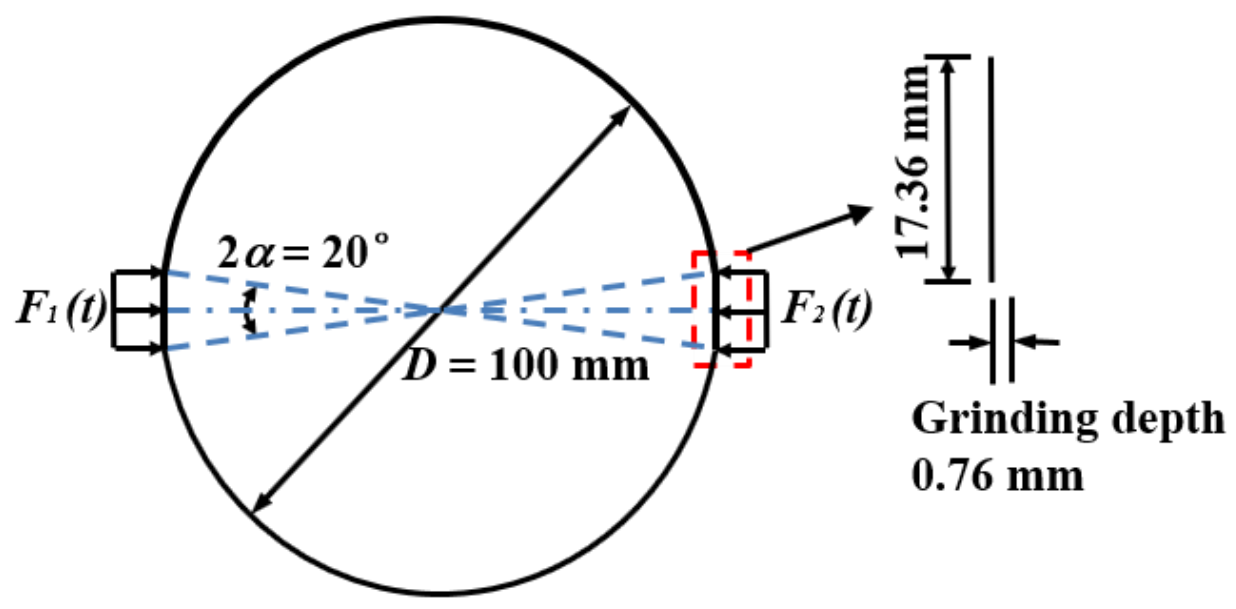

Fig. 3. Schematic diagram showing the preparation of Brazilian disc sample for splitting tensile tests.

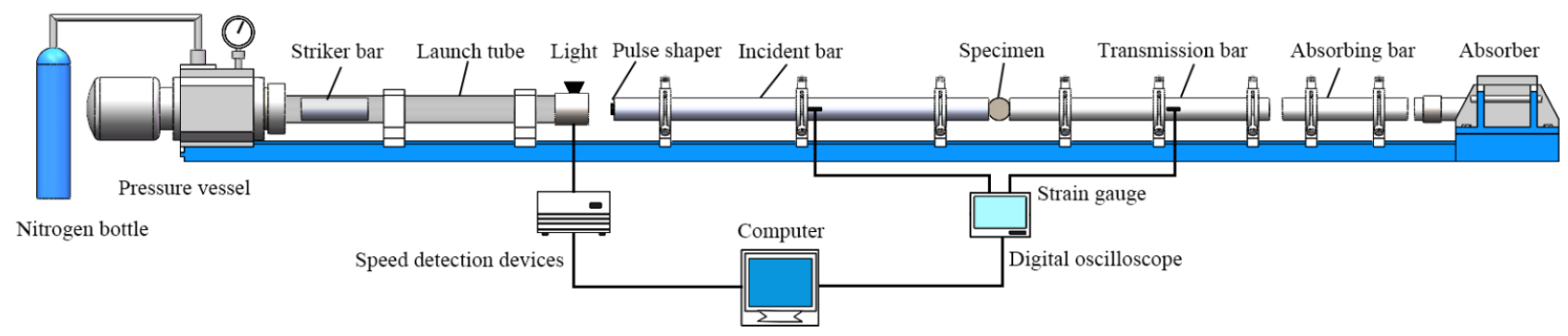

Fig. 4. Schematic diagram of SHPB testing system.

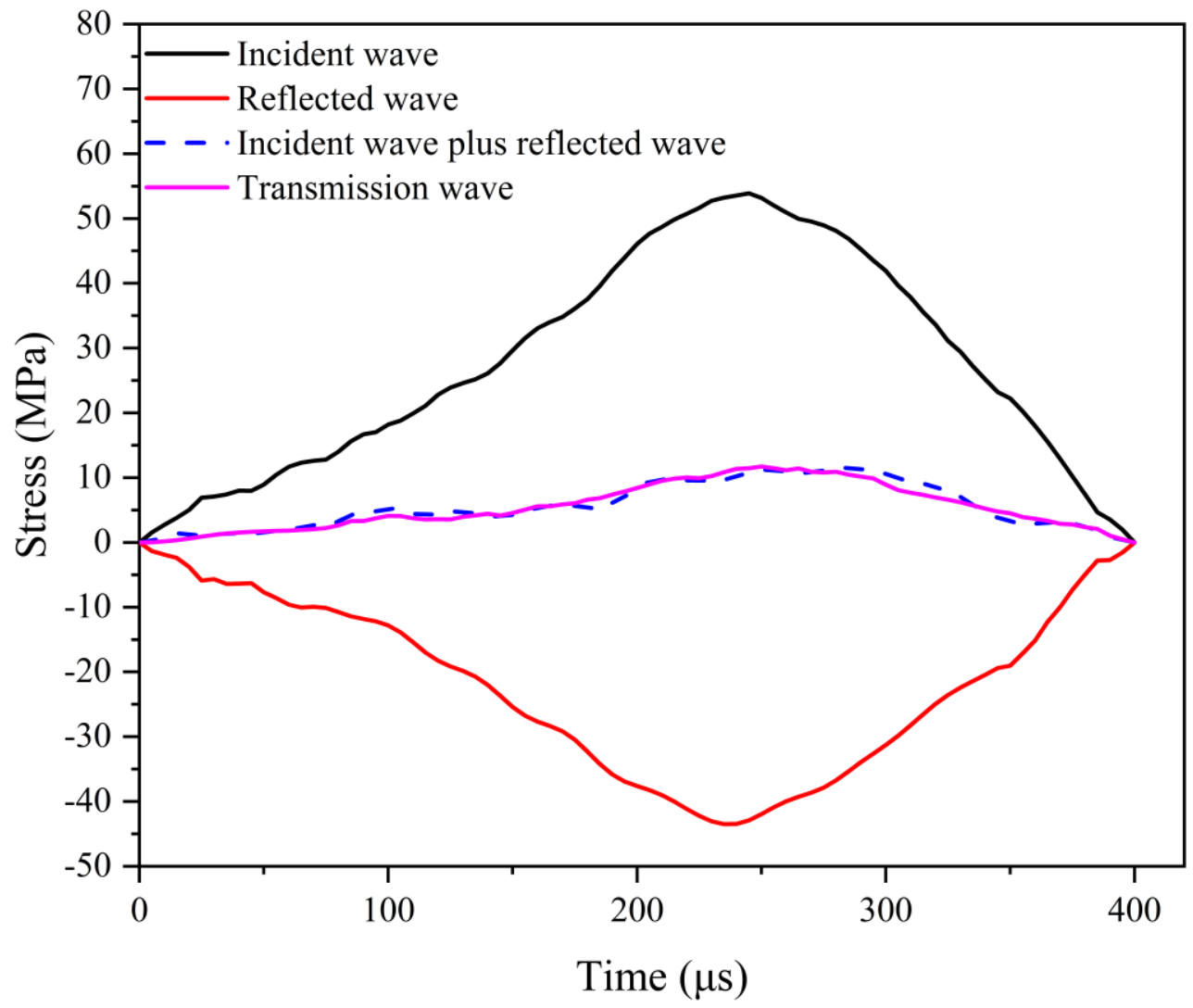

Fig. 5. An example of checking the stress equilibrium. 


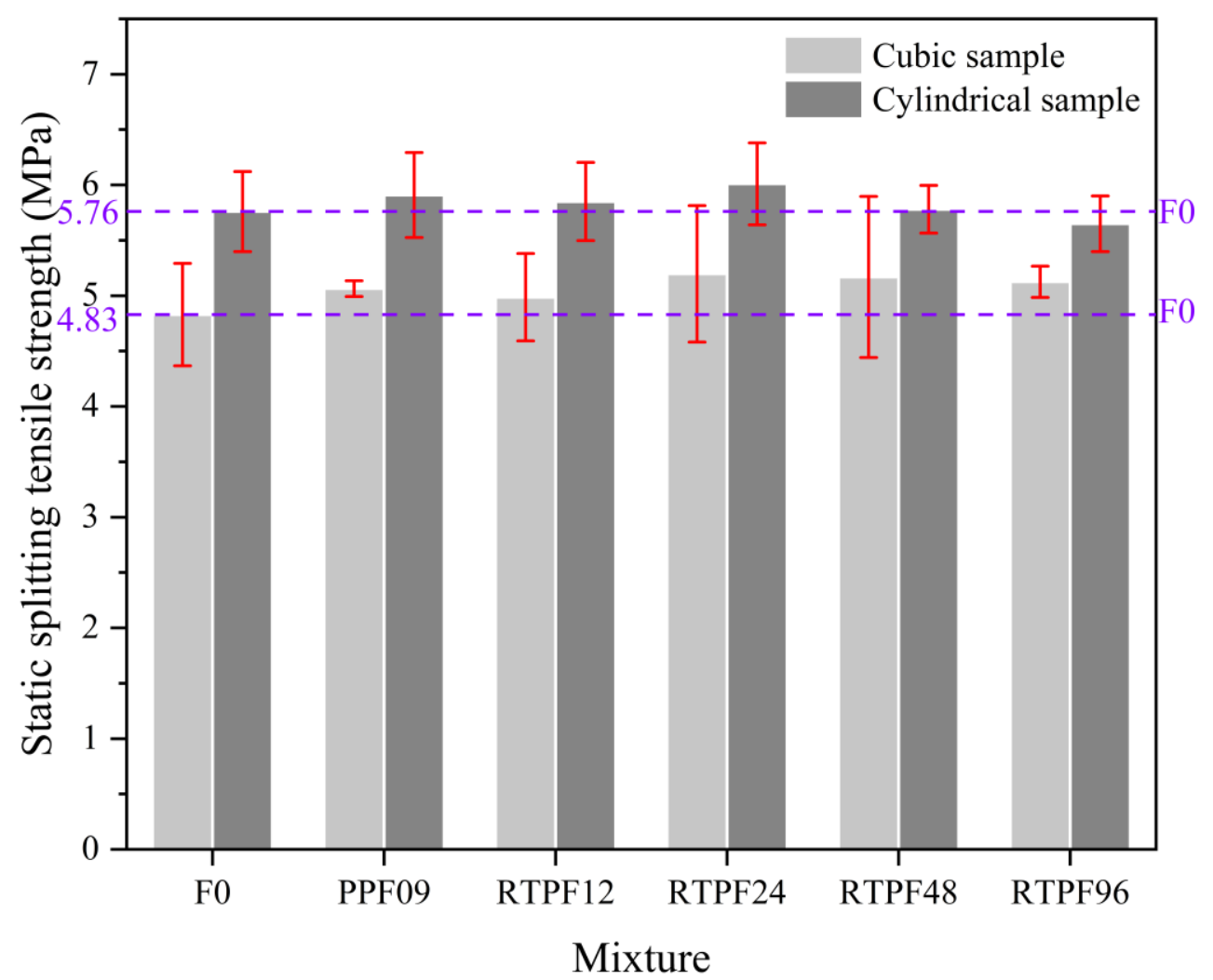

Fig. 6. Static splitting tensile strength of all mixtures.

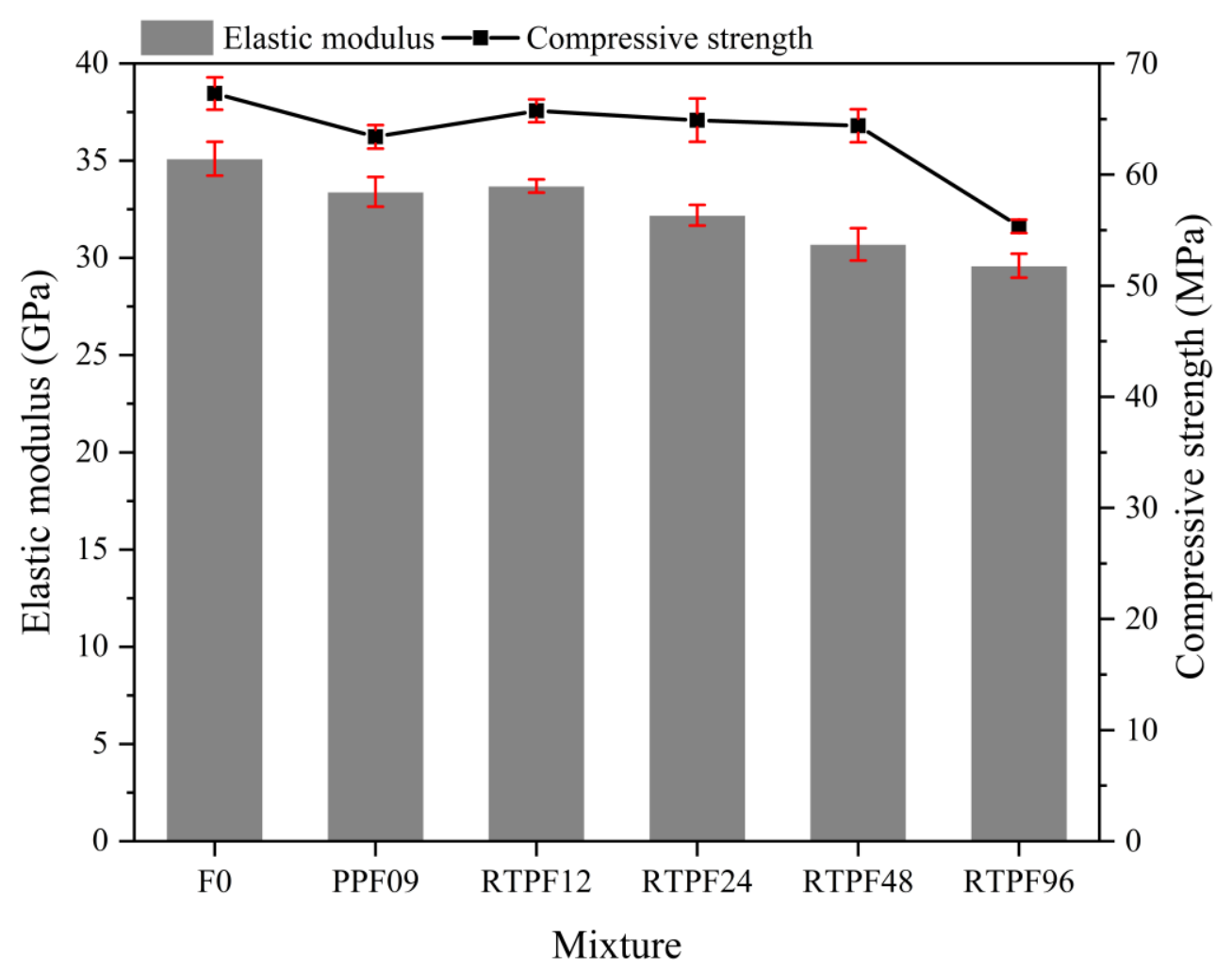

Fig. 7. Elastic modulus and compressive strength of all mixtures. 

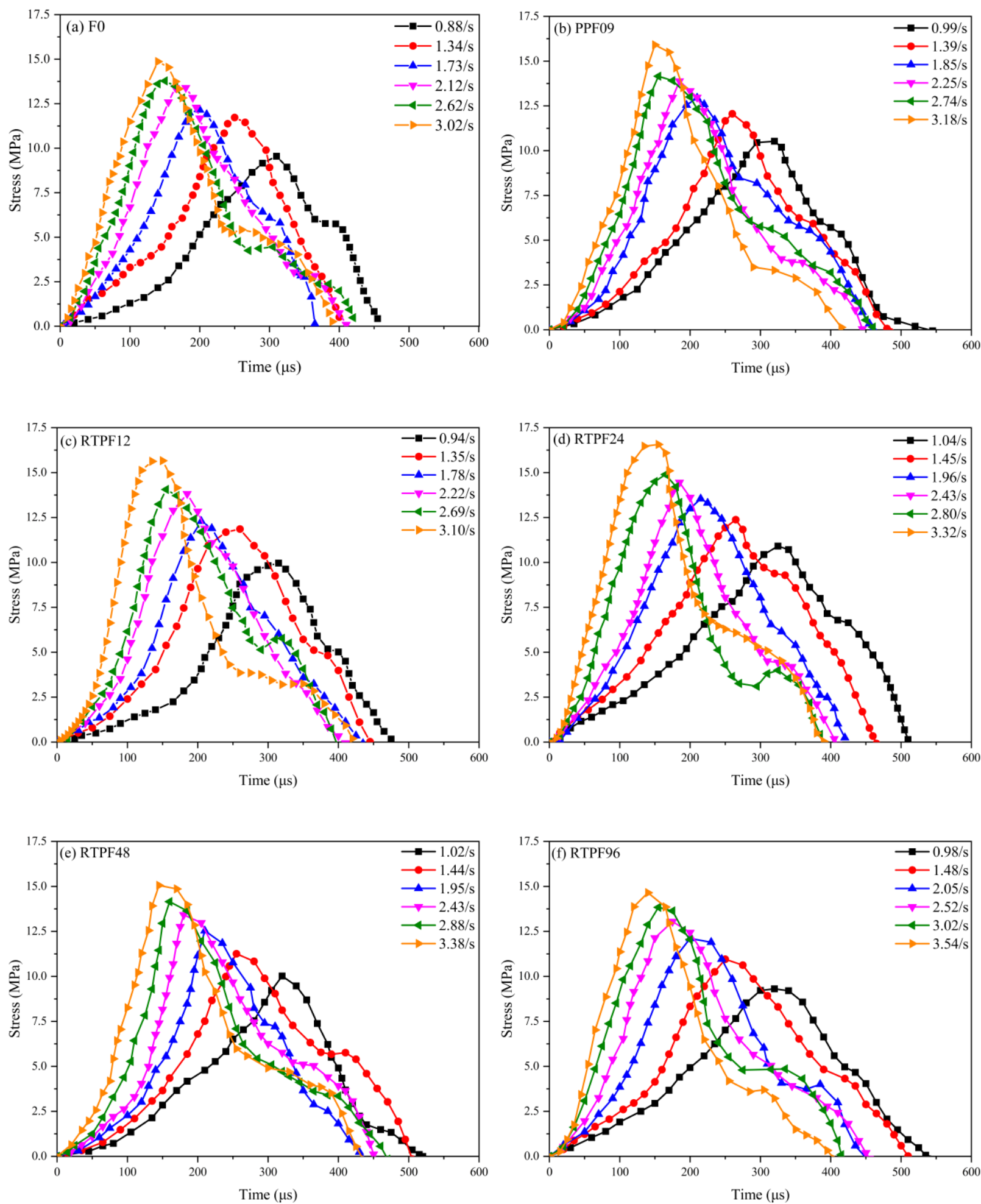

Fig. 8. Effect of strain rate on stress-time curves of: (a) F0; (b) PPF09; (c) RTPF12; (d) RTPF24;

(e) RTPF48; and (f) RTPF96. 


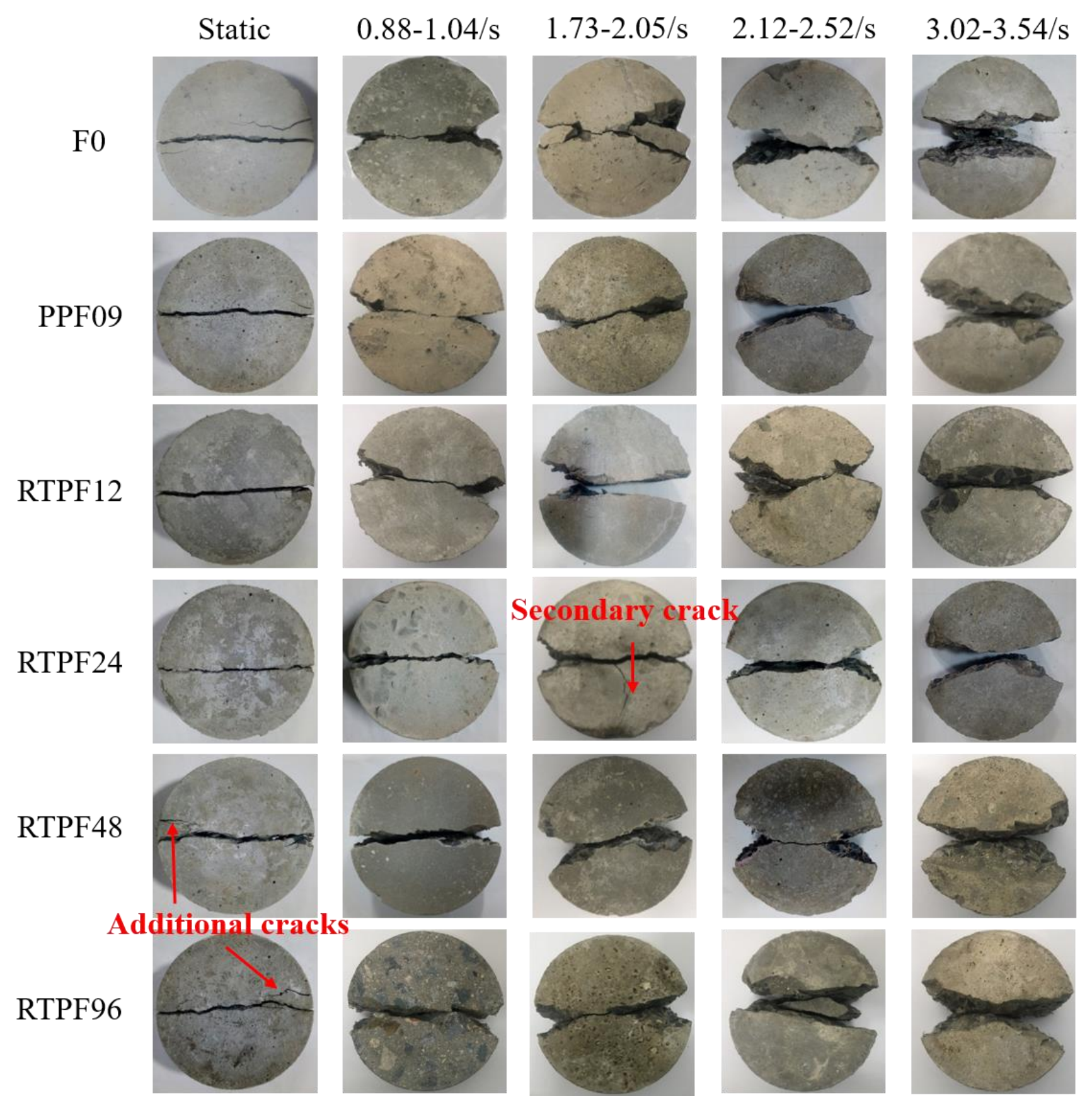

Fig. 9. Failure patterns of all mixtures under different strain rates. 


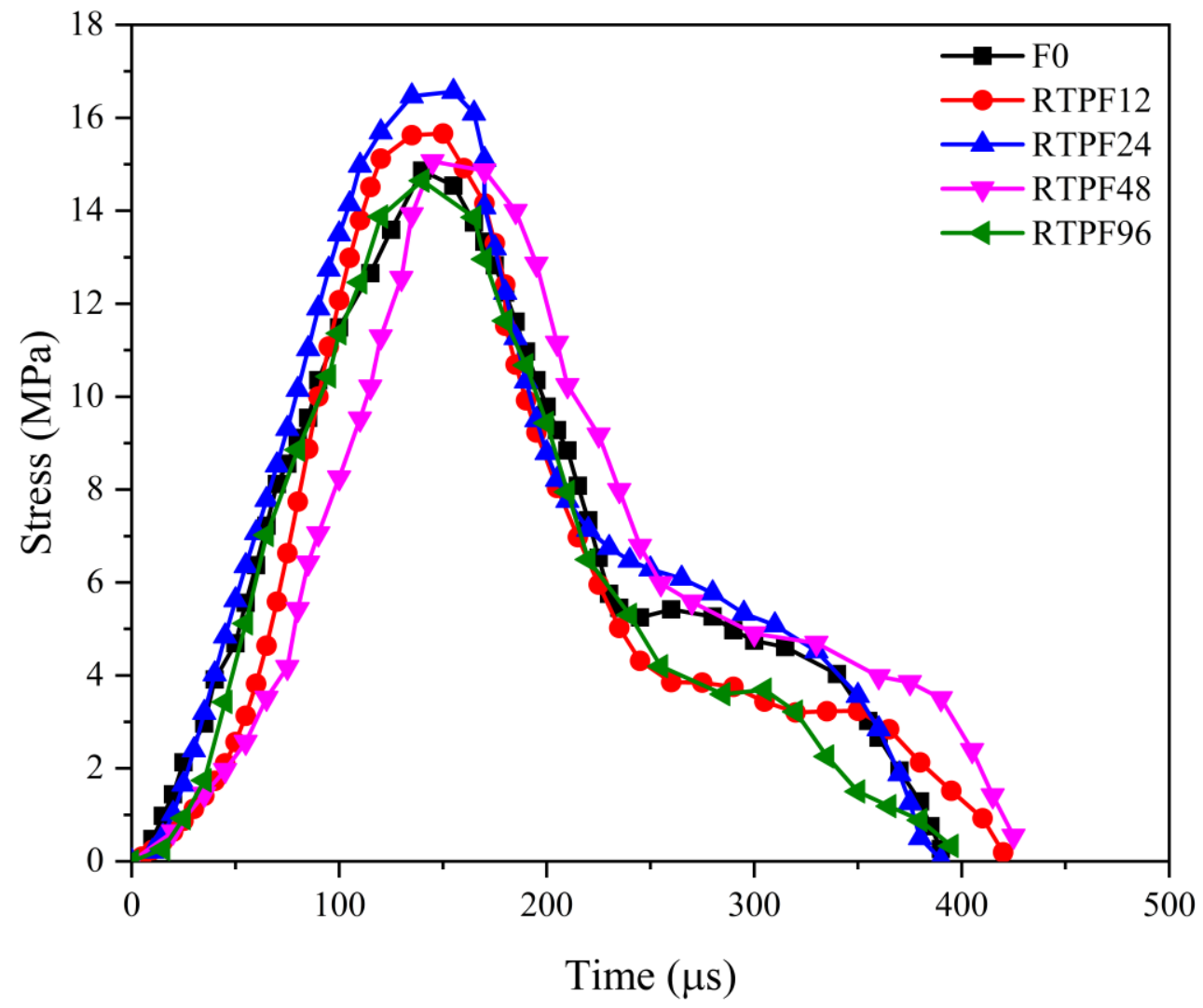

Fig. 10. Effect of RTP fibre on stress-time curve of concrete at strain rates of 3.02-3.54/s.

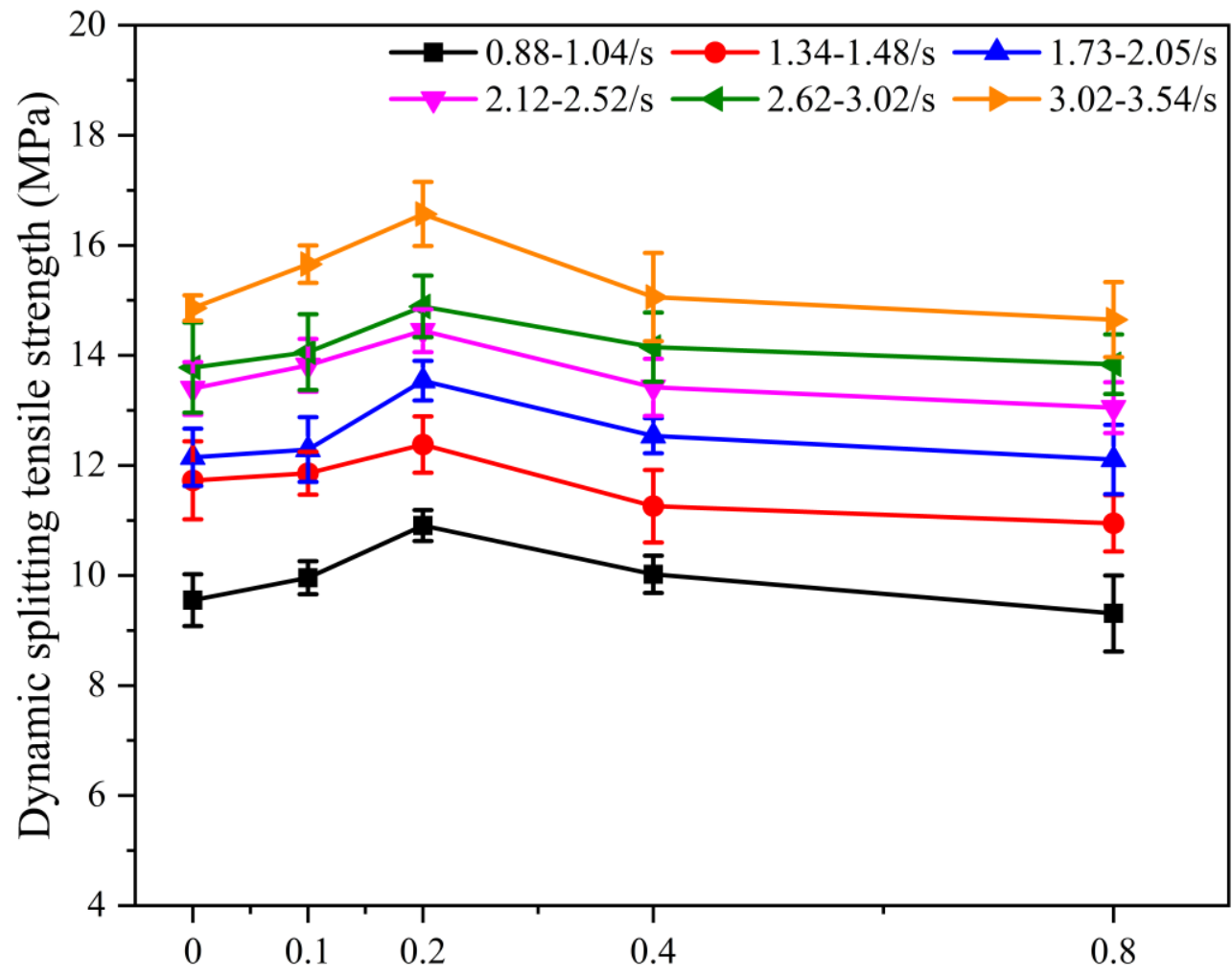

Fibre content (vol\%)

Fig. 11. Effect of RTP fibre content on dynamic splitting tensile strength of concrete under different strain rates. 

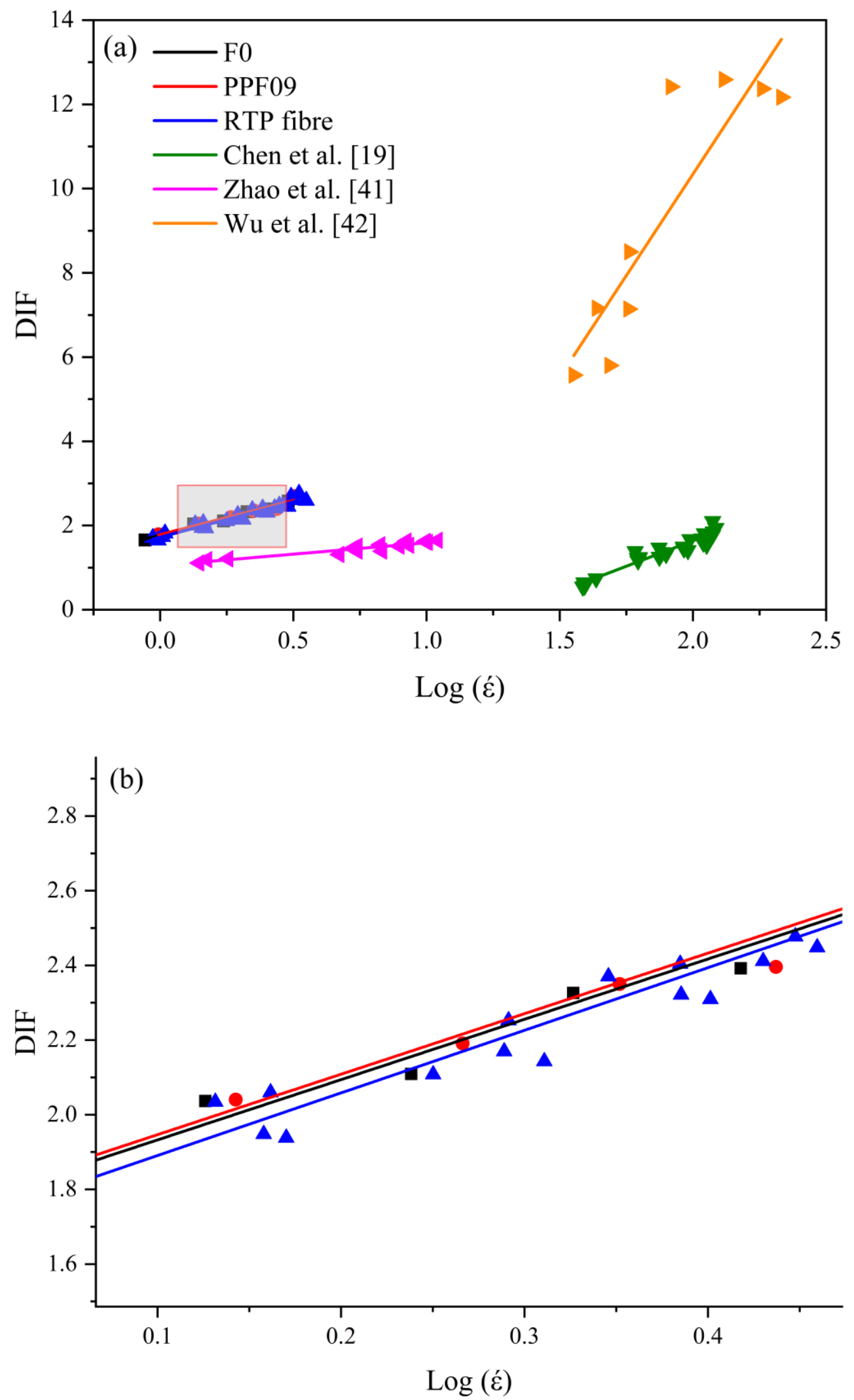

Fig. 12. Fitted curves of dynamic increase factor (DIF) of fibre reinforced concrete (FRC) against strain rate. 


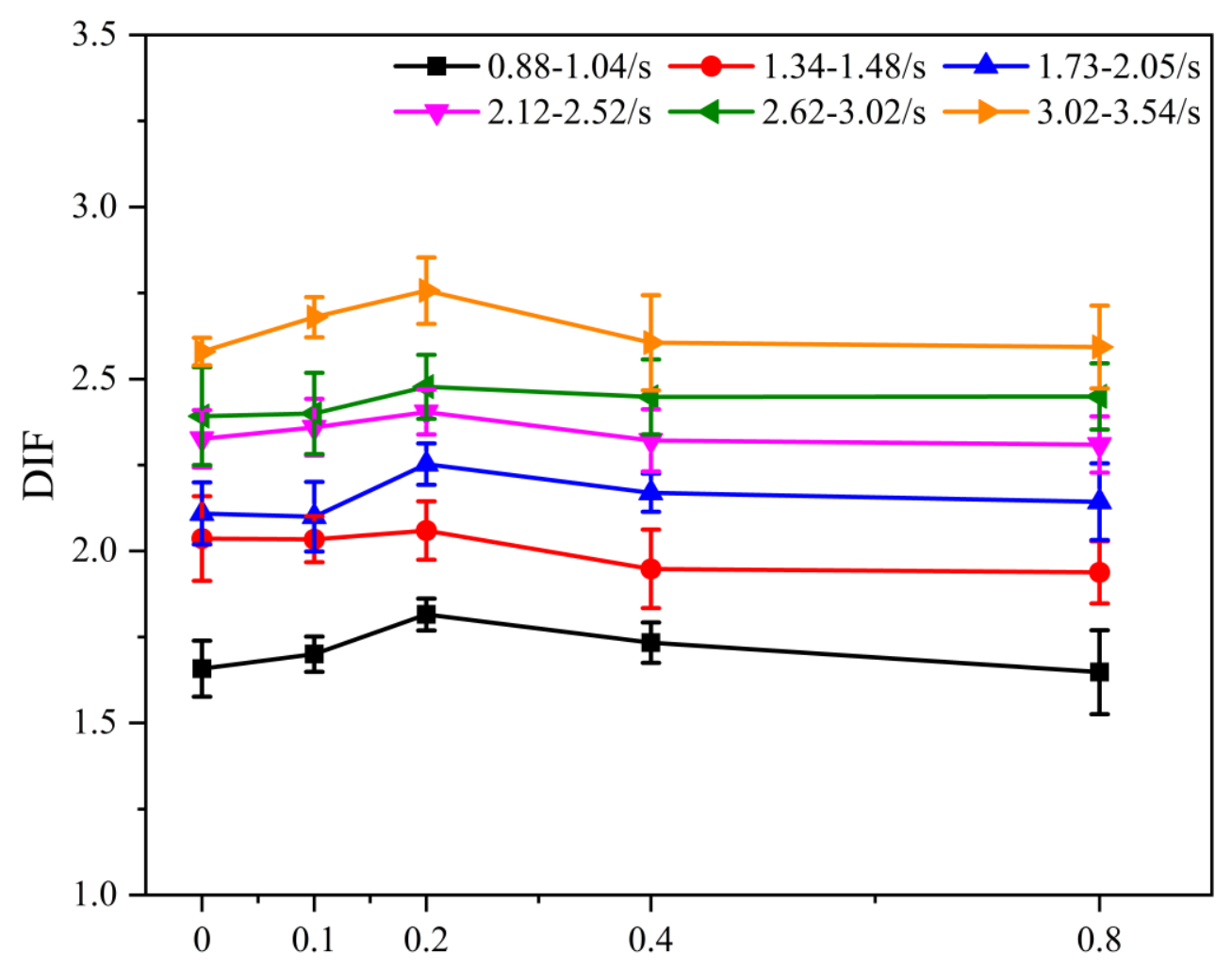

Fibre content (vol\%)

Fig. 13. Effect of RTP fibre content on dynamic increase factor (DIF) of concrete under different strain rates.

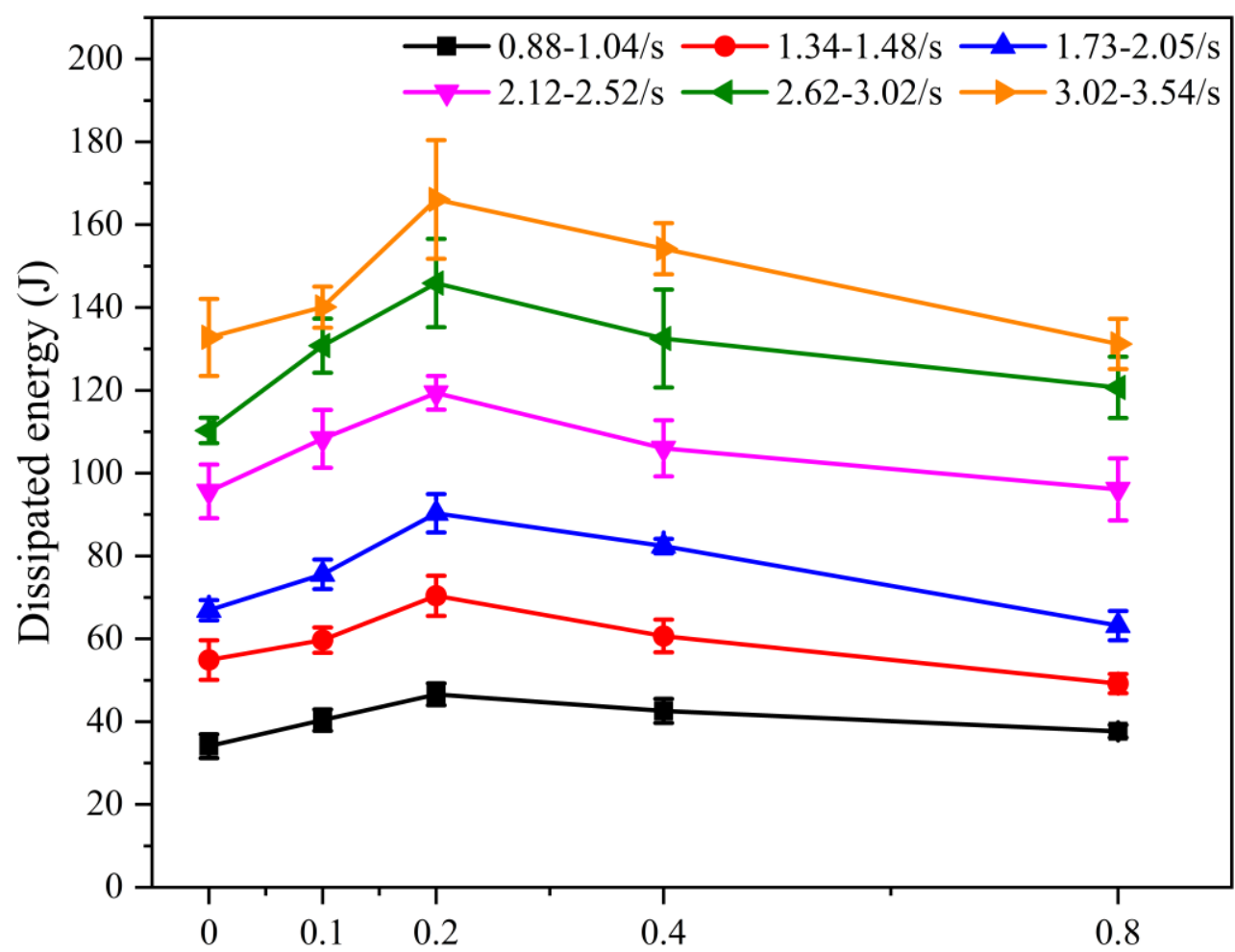

Fibre content (vol\%)

Fig. 14. Effect of RTP fibre content on dissipated energy of concrete under different strain rates. 

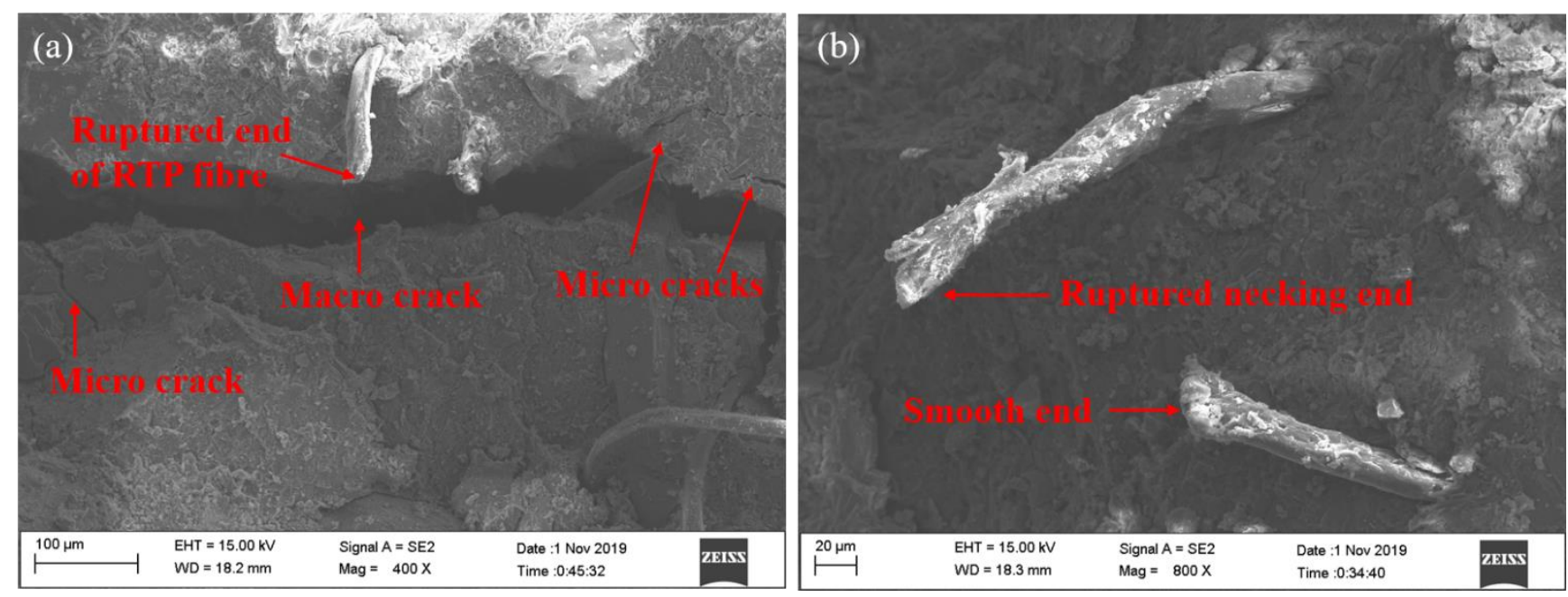

Fig. 15. SEM micrographs of RTP fibres inside the FRC after SHPB test.

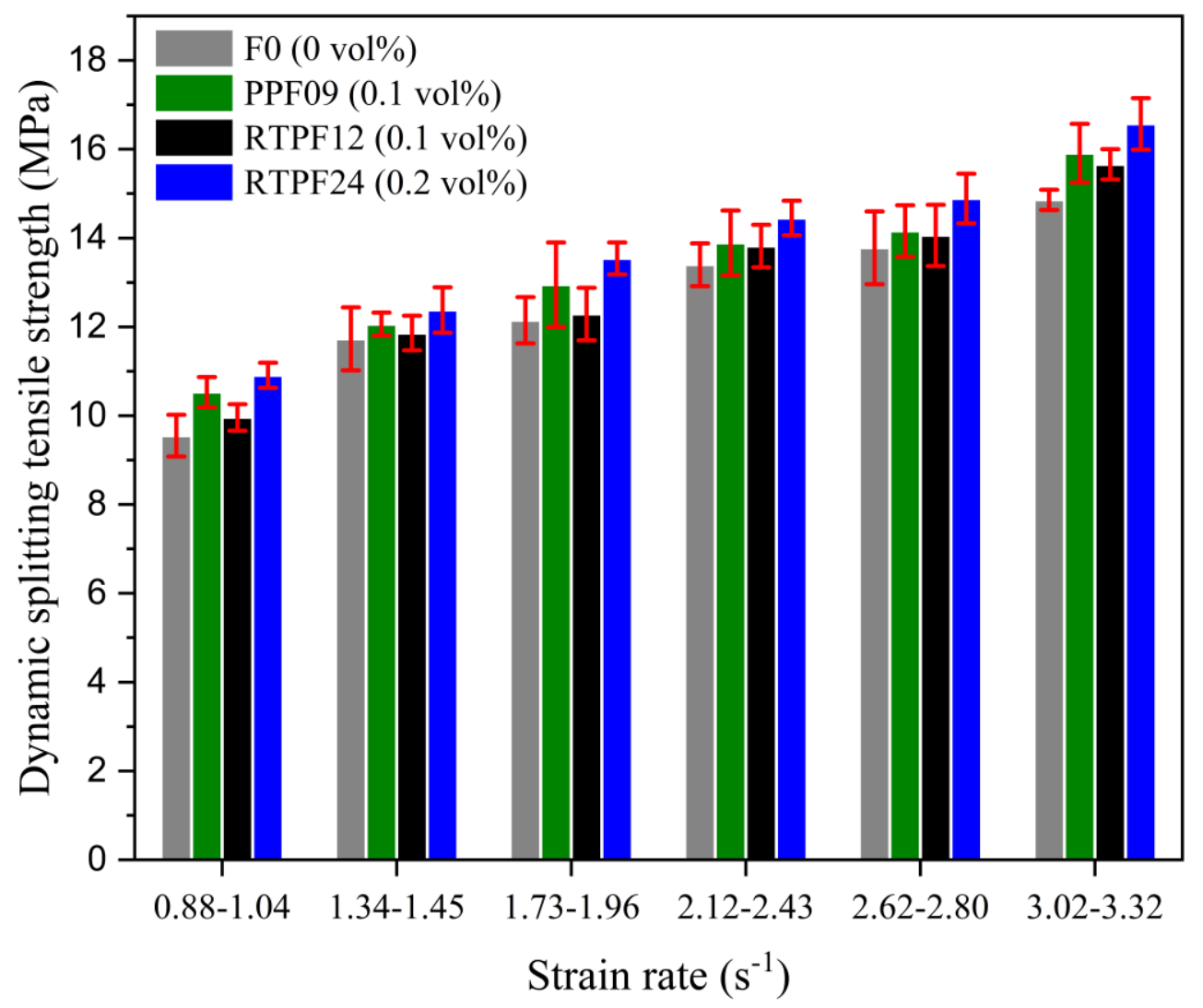

Fig. 16. Comparison of PP and RTP fibre effects on dynamic splitting tensile strength of concrete. 


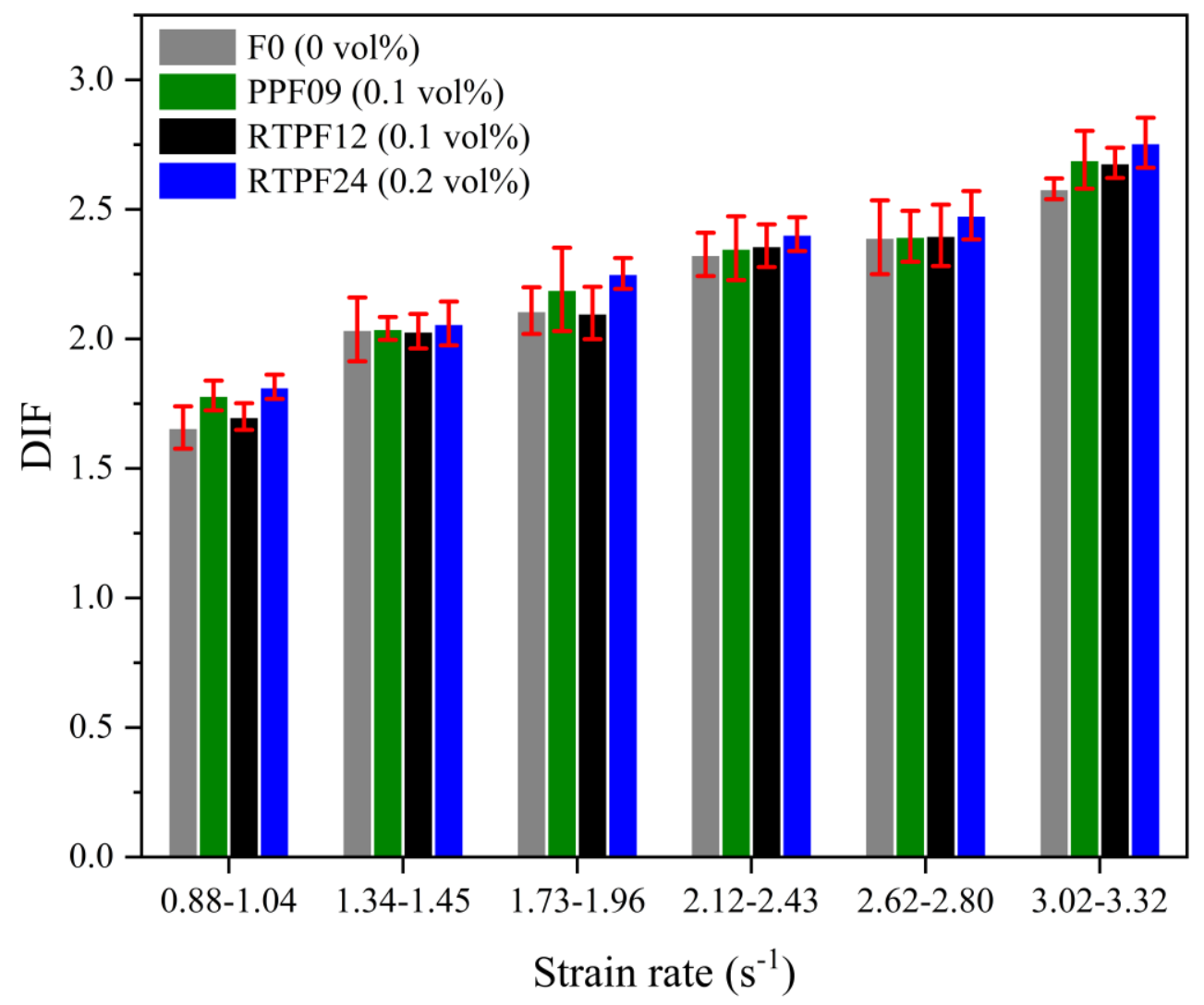

Fig. 17. Comparison of PP and RTP fibre effects on dynamic increase factor (DIF) of concrete.

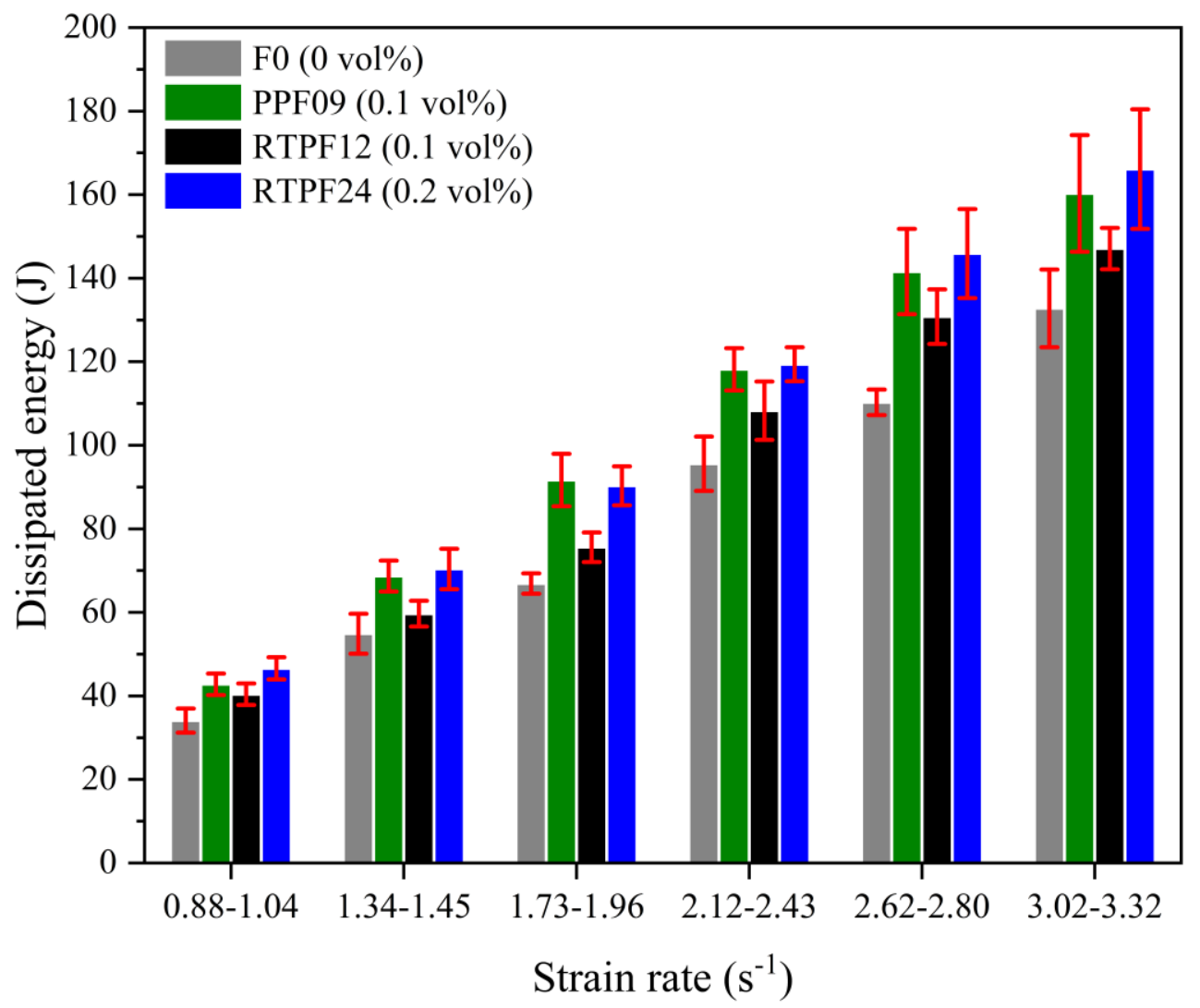

Fig. 18. Comparison of PP and RTP fibre effects on dissipated energy of concrete. 
Workability: $\uparrow 7.6 \%$

RTPF12 (0.1 vol\%)

Air content: $\downarrow 13.3 \%$

Compressive strength: $\uparrow 3.7 \%$

Flexural strength: $\downarrow 4.8 \%$

Splitting tensile strength: $\downarrow 1.5 \%$

Elastic modulus: $\uparrow 0.9 \%$

Dynamic compressive strength: $\downarrow 7.0 \%-\uparrow 2.2 \%$

Fracture energy under dynamic compression: $\downarrow 31.9 \%$ -

$\uparrow 18.8 \%$

Dynamic splitting tensile strength: $\downarrow 5.4 \%-\downarrow 0.5 \%$

Dissipated energy under dynamic splitting tension: $\downarrow$

$17.6 \%-\downarrow 5.6 \%$

\begin{tabular}{|l}
\multicolumn{1}{c}{ RTPF24 (0.2 vol\%) } \\
Workability: $\downarrow 5.1 \%$ \\
Air content: $\downarrow 8.3 \%$ \\
Compressive strength: $\uparrow 2.4 \%$ \\
FPF09 (0.1 vol\%)
\end{tabular} $\begin{aligned} & \text { Flexural strength: } \uparrow 0.8 \% \\
& \text { Splitting tensile strength: } \uparrow 2.7 \% \\
& \text { Elastic modulus: } \downarrow 3.6 \% \\
& \text { Dynamic compressive strength: } \downarrow 5.2 \%-\uparrow 8.6 \% \\
& \text { Fracture energy under dynamic compression : } \uparrow 3.8 \%-\uparrow \\
& 31.4 \% \\
& \\
& \text { Dynamic splitting tensile strength: } \uparrow 2.7 \%-\uparrow 5.2 \% \\
& \text { Dissipated energy under dynamic splitting tension }: \downarrow \\
& 1.5 \%-\uparrow 8.9 \%\end{aligned}$

Fig. 19. Comparison between specimens RTPF12/RTPF24 and PPF09 in terms of workability, static and dynamic mechanical properties (adopted from [19, 20]).

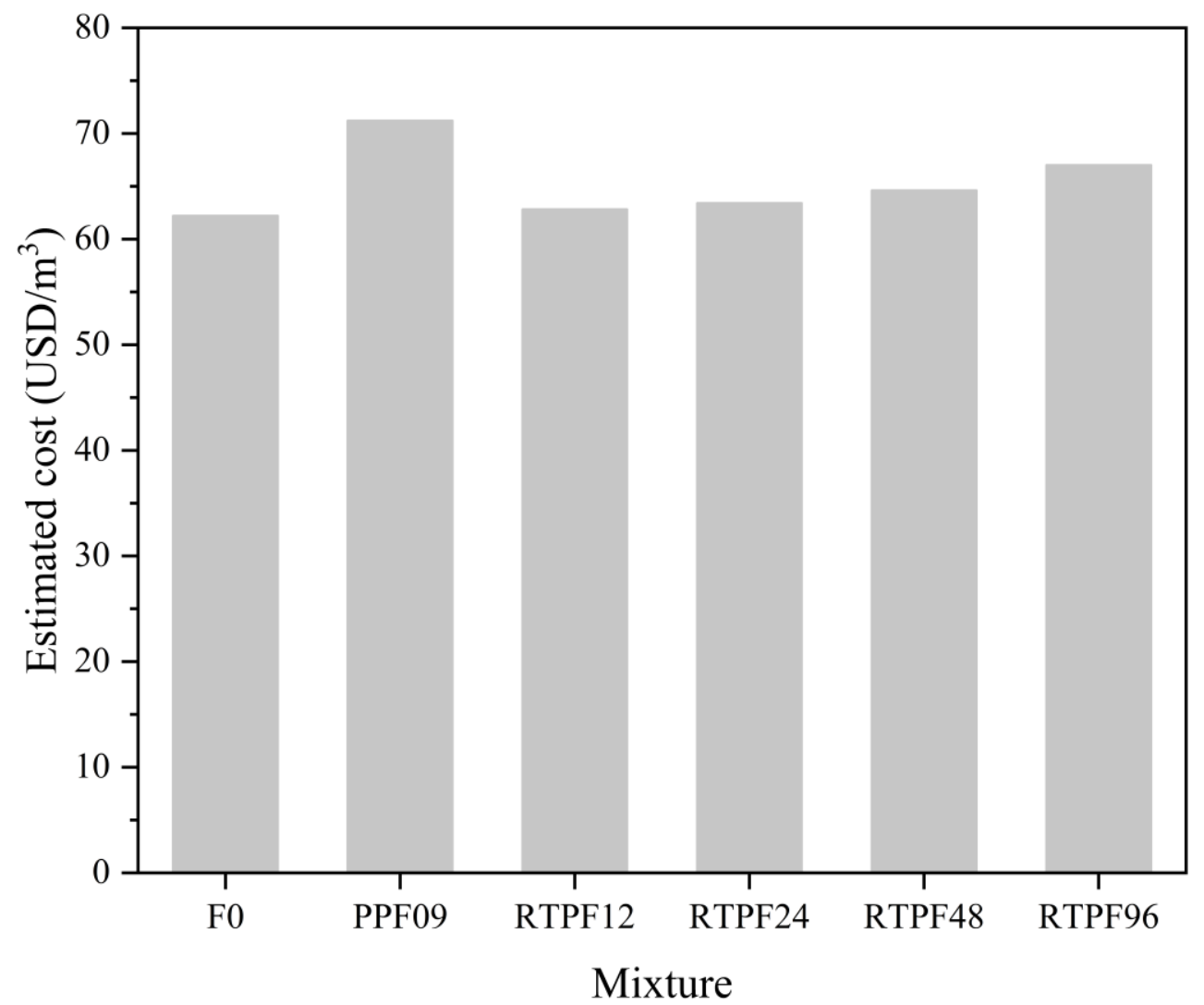

Fig. 20. Estimated cost of all mixtures per $\mathrm{m}^{3}$. 
Table 1. Summary of previous studies on effect of recycled tyre polymer (RTP) fibre on concrete.

\begin{tabular}{|c|c|c|c|c|}
\hline Refs. & Specimen & Fibre type and content & Properties measured & Concluding remarks \\
\hline Huang et al. [13] & Concrete & $\begin{array}{l}\text { Cleaned } \mathrm{RTP}^{1}: 1,2 \text { and } 7 \\
\mathrm{~kg} / \mathrm{m}^{3} ; \\
\mathrm{PP}: 2 \mathrm{~kg} / \mathrm{m}^{3}\end{array}$ & $\begin{array}{l}\text { Fire spalling and residual } \\
\text { compressive strength }\end{array}$ & $\begin{array}{l}\text { Mixtures containing RTP fibres over } 2 \\
\mathrm{~kg} / \mathrm{m}^{3} \text { exhibited enhanced fire resistance. }\end{array}$ \\
\hline Serdar et al. [14] & Concrete & $\begin{array}{l}\text { As-received RTP } 2: 5,10 \\
\text { and } 15 \mathrm{~kg} / \mathrm{m}^{3} \\
\text { PP: } 1 \mathrm{~kg} / \mathrm{m}^{3}\end{array}$ & $\begin{array}{l}\text { Density and air content, slump, } \\
\text { compressive strength, } \\
\text { autogenous shrinkage, } \\
\text { restrained shrinkage, and total } \\
\text { shrinkage }\end{array}$ & $\begin{array}{l}\text { - The workability was not obviously } \\
\text { weakened by the addition of RTP fibres. } \\
\text { - The autogenous shrinkage was } \\
\text { considerably reduced by the addition of } 15 \\
\mathrm{~kg} / \mathrm{m}^{3} \mathrm{RTP} \text { fibre. }\end{array}$ \\
\hline $\begin{array}{l}\text { Onuaguluchi and } \\
\text { Banthia [15] }\end{array}$ & Mortar & $\begin{array}{l}\text { As-received RTP: } 0.2 \% \text {, } \\
0.3 \% \text { and } 0.4 \% \text { by mass of } \\
\text { cement; } \\
\text { PET: } 0.2 \%, 0.3 \% \text { and } 0.4 \% \\
\text { by mass of cement }\end{array}$ & $\begin{array}{l}\text { Plastic shrinkage, crack } \\
\text { characterization, } \\
\text { microstructure after hot water } \\
\text { curing of } 90 \mathrm{~d}, \text { sulphate } \\
\text { resistance, and longitudinal } \\
\text { expansion }\end{array}$ & $\begin{array}{l}\text { - The plastic shrinkage resistance was } \\
\text { enhanced by incorporating } 0.4 \% \text { RTP fibre } \\
\text { into mortar, which was comparable to that } \\
\text { of mortar reinforced with } 0.3 \% \text { PET fibre. } \\
\text { - The durability was not impaired by the } \\
\text { incorporation of RTP fibres. } \\
\text { - The evolution of heat of hydration was } \\
\text { not influenced by the presence of either } \\
\text { RTP or PP fibres. }\end{array}$ \\
\hline Baricevic et al. [12] & Concrete & $\begin{array}{l}\text { As-received RTP: } 5,10 \text { and } \\
15 \mathrm{~kg} / \mathrm{m}^{3} \text {; } \\
\text { Cleaned RTP: } 1,2 \text { and } 5 \\
\mathrm{~kg} / \mathrm{m}^{3} ; \\
\text { PP: } 1 \mathrm{~kg} / \mathrm{m}^{3}\end{array}$ & $\begin{array}{l}\text { Density and air content, slump, } \\
\text { early-age deformation, } \\
\text { compressive strength, elastic } \\
\text { modulus, and freeze-thaw } \\
\text { resistance }\end{array}$ & $\begin{array}{l}\text { The early-age deformation of concrete } \\
\text { was reduced by the incorporation of RTP } \\
\text { fibres regardless of number of rubber } \\
\text { granules attached. } \\
\text { - The freeze-thaw resistance of concrete } \\
\text { was significantly improved by adding as- } \\
\text { received RTP fibres. }\end{array}$ \\
\hline $\begin{array}{l}\text { Baricevic et } \\
\text { al. [16] }\end{array}$ & Concrete & $\begin{array}{l}\text { As-received RTP: } 0.9 \text { and } \\
1.8 \mathrm{~kg} / \mathrm{m}^{3} ; \\
\text { PP: } 0.9 \text { and } 1.8 \mathrm{~kg} / \mathrm{m}^{3}\end{array}$ & $\begin{array}{l}\text { Density, slump, compressive } \\
\text { strength, flexural strength, } \\
\text { capillary absorption, gas } \\
\text { permeability, freeze-thaw } \\
\text { resistance, air void } \\
\text { characterization, pore size } \\
\text { distribution, autogenous }\end{array}$ & $\begin{array}{l}\text { - The early-age shrinkage resistance of } \\
\text { concrete reinforced with RTP fibres was } \\
\text { improved compared with that without fibre } \\
\text { reinforcement and that with PP fibre } \\
\text { incorporation. }\end{array}$ \\
\hline
\end{tabular}


shrinkage, and restrained shrinkage

Onuaguluchi and Banthia

[17]

Mortar and

concrete

As-received RTP: 0.35 and 0.7 vol\%

As-received RTP: 0.1\%,

Chen et al.

[19]

Concrete

$0.2,0.4$ and 0.8 vol\%; PP: 0.1 vol\%

As-received RTP: $0.1 \%$,

Chen et al.

[20]

Concrete
Flexural residual strength, post-crack flexural properties, and abrasion resistance

Slump, compressive strength, dynamic compressive properties, and microstructure

Air content, flexural fatigue properties, and microstructure
- The overall concrete behaviour was improved when PP fibres were replaced with RTP fibres.

- A positive synergistic effect can be formed when combining RTP fibres with either steel or PP fibres.

- No significant influence was found when RTP fibres were incorporated in concrete.

- The compressive properties under different strain rates were improved with the addition of RTP fibres up to $0.2 \mathrm{vol} \%$ where the optimal RTP fibre dosage was regarded as $0.2 \mathrm{vol} \%$.

- 0.1 vol\% PP fibre can be replaced with 0.2 vol\% RTP fibre considering overall static and dynamic compressive properties. - The flexural strength was slightly improved by the incorporation of RTP fibres (i.e. enhanced by 3.6 to $9.6 \%$ ).

- With the incorporation of RTP fibres of 0.2-0.4 vol\%, the overall fatigue behaviour was improved.

Note: RTP (recycled tyre polymer); PP (polypropylene); PET (polyethylene terephthalate); SHPB (split Hopkinson pressure bar); SEM (scanning electron microscope); BSE (back-scattered electron); ${ }^{1}$ (after certain cleaning process before usage); ${ }^{2}$ (without any cleaning process before usage). 
Table 2. Chemical compositions (wt\%) of cement.

\begin{tabular}{lllllllll}
\hline Oxide & $\mathrm{CaO}$ & $\mathrm{SiO}_{2}$ & $\mathrm{Al}_{2} \mathrm{O}_{3}$ & $\mathrm{Fe}_{2} \mathrm{O}_{3}$ & $\mathrm{MgO}$ & $\mathrm{SO}_{3}$ & $\mathrm{Na}_{2} \mathrm{O}$ & LOI \\
\hline Cement & 60.56 & 21.35 & 5.98 & 2.91 & 2.22 & 2.05 & 0.21 & 4.72 \\
\hline
\end{tabular}

Note: LOI (loss on ignition).

Table 3. Properties of fibres used in this study.

\begin{tabular}{llllll}
\hline Fibre type & $\begin{array}{l}\text { Length } \\
(\mathrm{mm})\end{array}$ & $\begin{array}{l}\text { Diameter } \\
(\mu \mathrm{m})\end{array}$ & $\begin{array}{l}\text { Density } \\
\left(\mathrm{kg} / \mathrm{m}^{3}\right)\end{array}$ & $\begin{array}{l}\text { Tensile strength } \\
(\mathrm{MPa})\end{array}$ & $\begin{array}{l}\text { Elastic modulus } \\
(\mathrm{GPa})\end{array}$ \\
\hline PP & 19 & 26 & 910 & 376 & 3.79 \\
RTP & $8.7 \pm 4.1$ & $21.1 \pm 2.5$ & 1160 & 475 & 3.21 \\
\hline
\end{tabular}

Table 4. Mix proportions.

\begin{tabular}{lllllllll}
\hline Symbol & $\begin{array}{l}\text { Cement } \\
\left(\mathrm{kg} / \mathrm{m}^{3}\right)\end{array}$ & $\begin{array}{l}\mathrm{FA} \\
\left(\mathrm{kg} / \mathrm{m}^{3}\right)\end{array}$ & $\begin{array}{l}\text { CA } \\
\left(\mathrm{kg} / \mathrm{m}^{3}\right)\end{array}$ & $\begin{array}{l}\text { Water } \\
\left(\mathrm{kg} / \mathrm{m}^{3}\right)\end{array}$ & $\begin{array}{l}\text { SP } \\
\left(\mathrm{kg} / \mathrm{m}^{3}\right)\end{array}$ & $\begin{array}{l}\text { RTP } \\
(\mathrm{vol} \%)\end{array}$ & $\begin{array}{l}\text { PP } \\
(\mathrm{vol} \%)\end{array}$ & $\begin{array}{l}\text { Slump } \\
(\mathrm{mm})\end{array}$ \\
\hline F0 & 550 & 560 & 1128 & 154 & 5.5 & 0 & 0 & 185 \\
PPF09 & 550 & 560 & 1128 & 154 & 5.5 & 0 & 0.1 & 158 \\
RTPF12 & 550 & 560 & 1128 & 154 & 5.5 & 0.1 & 0 & 170 \\
RTPF24 & 550 & 560 & 1128 & 154 & 5.5 & 0.2 & 0 & 150 \\
RTPF48 & 550 & 560 & 1128 & 154 & 5.5 & 0.4 & 0 & 120 \\
RTPF96 & 550 & 560 & 1128 & 154 & 5.5 & 0.8 & 0 & 70 \\
\hline
\end{tabular}

Note: FA (fine aggregate); CA (coarse aggregate); SP (superplasticiser).

Table 7. Summary of the fitted dynamic increase factor (DIF) equations for the curves in Fig. 12.

\begin{tabular}{lll}
\hline Legend & Fitted equation of DIF & $R^{2}$ \\
\hline F0 & $D I F=1.616 \log \dot{\varepsilon}+1.771$ & 0.979 \\
PPF09 & $D I F=1.621 \log \dot{\varepsilon}+1.785$ & 0.960 \\
RTP fibre & $D I F=1.678 \log \dot{\varepsilon}+1.723$ & 0.950 \\
Chen et al. [19] & $D I F=2.422 \log \dot{\varepsilon}-3.204$ & 0.913 \\
Zhao et al. [41] & $D I F=0.543 \log \dot{\varepsilon}+1.049$ & 0.890 \\
Wu et al. [42] & $D I F=9.635 \log \dot{\varepsilon}-8.923$ & 0.795 \\
\hline
\end{tabular}


Table 5. Number of specimens, achievable parameter and complied standard for each test.

\begin{tabular}{|c|c|c|c|c|c|c|c|c|c|c|c|c|}
\hline \multirow{3}{*}{ Symbol } & \multicolumn{2}{|l|}{ Slump test } & \multicolumn{4}{|c|}{ Splitting tension test } & \multicolumn{3}{|c|}{ Elastic modulus test } & \multicolumn{3}{|l|}{ SHPB test } \\
\hline & \multirow{2}{*}{$\begin{array}{l}\text { Achievable } \\
\text { parameter }\end{array}$} & \multirow[b]{2}{*}{ Standard } & \multicolumn{2}{|c|}{ Number of specimens } & \multirow{2}{*}{$\begin{array}{l}\text { Achievable } \\
\text { parameter }\end{array}$} & \multirow[b]{2}{*}{ Standard } & \multirow{2}{*}{$\begin{array}{l}\text { Number of } \\
\text { specimens }\end{array}$} & \multirow{2}{*}{$\begin{array}{l}\text { Achievable } \\
\text { parameter }\end{array}$} & \multirow[b]{2}{*}{ Standard } & \multirow{2}{*}{$\begin{array}{l}\text { Number of } \\
\text { specimens }\end{array}$} & \multirow{2}{*}{$\begin{array}{l}\text { Achievable } \\
\text { parameter }\end{array}$} & \multirow[b]{2}{*}{ Standard } \\
\hline & & & $\begin{array}{l}\text { Cubic } \\
\text { size }\end{array}$ & $\begin{array}{l}\text { Cylindrical } \\
\text { size }\end{array}$ & & & & & & & & \\
\hline F0 & \multirow{6}{*}{ Slump } & \multirow{6}{*}{$\begin{array}{l}\text { GB/T500 } \\
80-2016 \\
{[23]}\end{array}$} & 3 & 3 & \multirow{6}{*}{$f_{s t}$} & \multirow{6}{*}{$\begin{array}{l}\text { GB/T500 } \\
81-2002 \\
{[24]}\end{array}$} & 3 & \multirow{6}{*}{$E_{S}$} & & 18 & \multirow{6}{*}{$\begin{array}{l}\text { Stress-strain } \\
\text { curves, DIF, } \\
\text { dissipated } \\
\text { energy }\end{array}$} & \multirow{6}{*}{-} \\
\hline PPF09 & & & 3 & 3 & & & 3 & & & 18 & & \\
\hline RTPF12 & & & 3 & 3 & & & 3 & & GB/T5008 & 18 & & \\
\hline RTPF24 & & & 3 & 3 & & & 3 & & $\begin{array}{l}1-2002 \\
{[24]}\end{array}$ & 18 & & \\
\hline RTPF48 & & & 3 & 3 & & & 3 & & & 18 & & \\
\hline RTPF96 & & & 3 & 3 & & & 3 & & & 18 & & \\
\hline
\end{tabular}

Note: $f_{s t}$ (static splitting tensile strength); $E_{s}$ (elastic modulus); DIF (Dynamic increase factor) 
Table 6. Summary of dynamic properties of all mixtures obtained from SHPB tests.

\begin{tabular}{|c|c|c|c|c|c|c|c|}
\hline Symbol & $\begin{array}{l}\text { Average stress } \\
\text { rate }(\mathrm{GPa} / \mathrm{s})\end{array}$ & $\begin{array}{l}\text { Average strain } \\
\text { rate }\left(\mathrm{s}^{-1}\right)\end{array}$ & $f_{d s t}(\mathrm{MPa})$ & $f_{s t 1}(\mathrm{MPa})$ & $f_{s t 2}(\mathrm{MPa})$ & $\mathrm{DIF}, f_{d s t} / f_{s t 2}$ & $\begin{array}{l}\text { Dissipated } \\
\text { energy }(\mathrm{J})\end{array}$ \\
\hline \multirow[t]{6}{*}{ F0 } & 30.8 & 0.88 & $9.55 \pm 0.47$ & $4.83 \pm 0.46$ & $5.76 \pm 0.36$ & $1.66 \pm 0.08$ & $34.1 \pm 2.89$ \\
\hline & 46.9 & 1.34 & $11.73 \pm 0.71$ & $4.83 \pm 0.46$ & $5.76 \pm 0.36$ & $2.04 \pm 0.12$ & $54.9 \pm 4.78$ \\
\hline & 60.8 & 1.73 & $12.15 \pm 0.52$ & $4.83 \pm 0.46$ & $5.76 \pm 0.36$ & $2.11 \pm 0.09$ & $66.9 \pm 2.43$ \\
\hline & 74.4 & 2.12 & $13.40 \pm 0.48$ & $4.83 \pm 0.46$ & $5.76 \pm 0.36$ & $2.33 \pm 0.08$ & $95.6 \pm 6.49$ \\
\hline & 91.9 & 2.62 & $13.78 \pm 0.82$ & $4.83 \pm 0.46$ & $5.76 \pm 0.36$ & $2.39 \pm 0.14$ & $110.3 \pm 3.07$ \\
\hline & 106.1 & 3.02 & $14.86 \pm 0.23$ & $4.83 \pm 0.46$ & $5.76 \pm 0.36$ & $2.58 \pm 0.04$ & $132.8 \pm 9.30$ \\
\hline \multirow[t]{6}{*}{ PPF09 } & 32.9 & 0.99 & $10.53 \pm 0.34$ & $5.06 \pm 0.07$ & $5.91 \pm 0.38$ & $1.78 \pm 0.06$ & $42.8 \pm 2.57$ \\
\hline & 46.4 & 1.39 & $12.06 \pm 0.26$ & $5.06 \pm 0.07$ & $5.91 \pm 0.38$ & $2.04 \pm 0.04$ & $68.7 \pm 3.69$ \\
\hline & 61.7 & 1.85 & $12.95 \pm 0.95$ & $5.06 \pm 0.07$ & $5.91 \pm 0.38$ & $2.19 \pm 0.16$ & $91.7 \pm 6.28$ \\
\hline & 75.1 & 2.25 & $13.89 \pm 0.73$ & $5.06 \pm 0.07$ & $5.91 \pm 0.38$ & $2.35 \pm 0.12$ & $118.2 \pm 5.07$ \\
\hline & 91.4 & 2.74 & $14.16 \pm 0.58$ & $5.06 \pm 0.07$ & $5.91 \pm 0.38$ & $2.40 \pm 0.10$ & $141.6 \pm 10.20$ \\
\hline & 106.1 & 3.18 & $15.91 \pm 0.66$ & $4.99 \pm 0.39$ & $5.91 \pm 0.38$ & $2.69 \pm 0.11$ & $160.3 \pm 13.95$ \\
\hline \multirow[t]{6}{*}{ RTPF12 } & 31.6 & 0.94 & $9.96 \pm 0.30$ & $4.99 \pm 0.39$ & $5.85 \pm 0.35$ & $1.70 \pm 0.05$ & $40.4 \pm 2.58$ \\
\hline & 45.6 & 1.35 & $11.86 \pm 0.39$ & $4.99 \pm 0.39$ & $5.85 \pm 0.35$ & $2.03 \pm 0.07$ & $59.7 \pm 3.08$ \\
\hline & 60.0 & 1.78 & $12.29 \pm 0.59$ & $4.99 \pm 0.39$ & $5.85 \pm 0.35$ & $2.10 \pm 0.10$ & $75.6 \pm 3.55$ \\
\hline & 74.7 & 2.22 & $13.82 \pm 0.48$ & $4.99 \pm 0.39$ & $5.85 \pm 0.35$ & $2.36 \pm 0.08$ & $108.3 \pm 6.99$ \\
\hline & 90.7 & 2.69 & $14.06 \pm 0.69$ & $4.99 \pm 0.39$ & $5.85 \pm 0.35$ & $2.40 \pm 0.12$ & $130.8 \pm 6.52$ \\
\hline & 104.4 & 3.10 & $15.66 \pm 0.34$ & $4.99 \pm 0.39$ & $5.85 \pm 0.35$ & $2.68 \pm 0.06$ & $147.1 \pm 4.96$ \\
\hline \multirow[t]{6}{*}{ RTPF24 } & 33.6 & 1.04 & $10.91 \pm 0.28$ & $5.20 \pm 0.62$ & $6.01 \pm 0.37$ & $1.82 \pm 0.05$ & $46.6 \pm 2.64$ \\
\hline & 46.7 & 1.45 & $12.38 \pm 0.51$ & $5.20 \pm 0.62$ & $6.01 \pm 0.37$ & $2.06 \pm 0.08$ & $70.4 \pm 4.83$ \\
\hline & 63.0 & 1.96 & $13.54 \pm 0.36$ & $5.20 \pm 0.62$ & $6.01 \pm 0.37$ & $2.25 \pm 0.06$ & $90.3 \pm 4.64$ \\
\hline & 78.1 & 2.43 & $14.45 \pm 0.39$ & $5.20 \pm 0.62$ & $6.01 \pm 0.37$ & $2.40 \pm 0.06$ & $119.4 \pm 4.06$ \\
\hline & 90.2 & 2.80 & $14.89 \pm 0.56$ & $5.20 \pm 0.62$ & $6.01 \pm 0.37$ & $2.48 \pm 0.09$ & $145.9 \pm 10.67$ \\
\hline & 106.9 & 3.32 & $16.57 \pm 0.58$ & $5.20 \pm 0.62$ & $6.01 \pm 0.37$ & $2.76 \pm 0.10$ & $166.1 \pm 14.31$ \\
\hline \multirow[t]{2}{*}{ RTPF48 } & 31.3 & 1.02 & $10.02 \pm 0.34$ & $5.17 \pm 0.73$ & $5.78 \pm 0.21$ & $1.73 \pm 0.06$ & $42.6 \pm 2.91$ \\
\hline & 44.2 & 1.44 & $11.26 \pm 0.66$ & $5.17 \pm 0.73$ & $5.78 \pm 0.21$ & $1.95 \pm 0.11$ & $60.7 \pm 3.94$ \\
\hline
\end{tabular}




\begin{tabular}{llllllll}
\hline & 59.7 & 1.95 & $12.54 \pm 0.32$ & $5.17 \pm 0.73$ & $5.78 \pm 0.21$ & $2.17 \pm 0.06$ & $82.4 \pm 1.77$ \\
& 74.6 & 2.43 & $13.42 \pm 0.52$ & $5.17 \pm 0.73$ & $5.78 \pm 0.21$ & $2.32 \pm 0.09$ & $106.0 \pm 6.79$ \\
& 88.4 & 2.88 & $14.15 \pm 0.63$ & $5.17 \pm 0.73$ & $5.78 \pm 0.21$ & $2.45 \pm 0.11$ & $132.5 \pm 11.83$ \\
RTPF96 & 103.9 & 3.38 & $15.06 \pm 0.80$ & $5.17 \pm 0.73$ & $5.78 \pm 0.21$ & $2.61 \pm 0.14$ & $154.2 \pm 6.20$ \\
& 29.1 & 0.98 & $9.31 \pm 0.69$ & $5.13 \pm 0.14$ & $5.65 \pm 0.48$ & $1.65 \pm 0.12$ & $37.7 \pm 1.52$ \\
& 43.8 & 1.48 & $10.95 \pm 0.51$ & $5.13 \pm 0.14$ & $5.65 \pm 0.48$ & $1.94 \pm 0.09$ & $49.2 \pm 2.31$ \\
& 60.6 & 2.05 & $12.11 \pm 0.63$ & $5.13 \pm 0.14$ & $5.65 \pm 0.48$ & $2.14 \pm 0.11$ & $63.2 \pm 3.56$ \\
& 74.6 & 2.52 & $13.05 \pm 0.46$ & $5.13 \pm 0.14$ & $5.65 \pm 0.48$ & $2.31 \pm 0.08$ & $96.1 \pm 7.49$ \\
& 89.3 & 3.02 & $13.84 \pm 0.54$ & $5.13 \pm 0.14$ & $5.65 \pm 0.48$ & $2.45 \pm 0.10$ & $120.7 \pm 7.41$ \\
& 104.6 & 3.54 & $14.65 \pm 0.68$ & $5.13 \pm 0.14$ & $5.65 \pm 0.48$ & $2.59 \pm 0.12$ & $131.2 \pm 6.07$ \\
\hline
\end{tabular}

Note: $f_{d s t}$ (dynamic splitting tensile strength); $f_{\text {st } 1}$ (static splitting tensile strength using cubic sample); $f_{\text {st } 2}$ (static splitting tensile strength using cylindrical sample). 